\title{
PROTECCIÓN JURÍDICO-SANITARIA FRENTE A LOS RIESGOS PROCEDENTES DE LAS INFRAESTRUCTURAS DE RADIOCOMUNICACIÓN
}

\author{
ANTONIO EDUARDO EMBID TELLO \\ Profesor ayudante de Derecho Administrativo \\ Universidad Carlos III (Madrid) \\ aembid@der-pu.uc3m.es
}

Recibido: 30 de marzo de 2010 / Aceptado: 7 de Mayo de 2010

RESUMEN: Los campos electromagnéticos (CEM) generan una amplia preocupación social, que ha llevado a un rechazo masivo a la instalación de antenas de telefonía móvil. Esto está justificado por la continua publicación de estudios científicos que apuntan a que dicha tecnología podría ser peligrosa. Algunas instituciones comunitarias mantienen que los límites de exposición a CEM actualmente vigentes no se ajustan a los objetivos de la Unión Europea en materia de protección de la salud pública.

La normativa comunitaria y española sobre protección frente a la radiación únicamente trata aquellos efectos conocidos (efectos térmicos), mientras que los efectos todavía inciertos (efectos no térmicos) no son combatidos. Esta normativa no limita ninguna emisión, puesto que los valores límite suelen quedar muy por encima de las emisiones efectivas utilizadas por las compañías de telecomunicaciones. La evaluación del riesgo implementada por el gobierno español es, asimismo, inadecuada, estando basada únicamente en los informes del sector industrial afectado.

Es en los niveles autonómico y local donde se han aprobado las medidas más estrictas para la protección del público de la exposición a CEM. La jurisprudencia y la doctrina continúan debatiendo sobre cuáles de dichas medidas son legítimas y cuáles no.

RESUM: Els camps electromagnètics (CEM) generen una àmplia preoupació social, que ha dut a un rebuig massiu a la instal·lació d'antenes de telefonia mòbil. Això està 
justificat per la publicació continuada d'estudis científics que apunte a què aquesta tecnologia podria ser perillosa. Algunes institucions comunitàries mantenen que els límits d'exposició a CEM actualment vigents no s'ajusten als objectius de la Unió Europea en matèria de protecció de la salut pública.

La normativa comunitària i espanyola sobre protecció davant la radiació únicament tracta d'aquells efectes coneguts (efectes tèrmics), mentre que els efectes encara incerts (efectes no tèrmics) no són combatuts. Aquesta normativa no limita cap emissió, ja que els valors límit acostumen a romandre molt per sobre de les emissions efectives utilitzades per les companyies de telecomunicacions. L'avaluació del risc implementada pel govern espanyol és, així mateix, inadequada, ja que es basa únicament en els informes del sector industrial afectat.

És en els nivells autonòmic i local on s'han aprovat les mesures més estrictes per a la protecció del públic de l'exposició a CEM. La jurisprudència i la doctrina continuen debatent sobre quines d'aquestes mesures són legítimes i quines no.

ABSTRACT: Electromagnetic fields (EMFs) generate a great social concern which has lead to a massive rejection to installation of mobile phone masts, due to the continuous publication of scientific studies which point out that these technologies may be dangerous. Some European Institutions maintain that the current boundary values for EMFs are not suitable to the EU objectives of health protection.

Communitarian and Spanish radiation protection normative protects only against known dangers (thermal effects), while the uncertain dangers (non thermal effects) are not engaged. No emission is limited by Spanish normative, since the recommended boundary values remain usually well above the effective emissions used by the telecommunications companies, and risk assessment implemented by the spanish government is also inadequate, being solely based on the reports of the involved industry.

It is in the autonomic and local regulation level where the strictest measures to protect the public from EMFs exposure have been taken. Spanish jurisprudence and doctrine still discuses which of these measures are legitimate and which of them aren't. 
PALABRAS CLAVE: Antenas — radiación no ionizante — salud pública — principio de precaución

PARAULES CLAU: Antenes — radiació no ionitzant — salut pública — principi de precaució

KEYWORDS: Masts — non-ionizing radiation — public health — precautionary principle

Sumario: I. Introducción. Radiación no ionizante y salud pública. 1. Preocupación social por los campos electromagnéticos. 2. Significado de la radiación y efectos sobre la salud. II. Regulación jurídico-sanitaria de los campos electromagnéticos. 1. Protección jurídica en la Unión Europea. 1.1. La recomendación del Consejo 1999/519/CE, de 12 de julio de 1999. 1.2. Las propuestas más protectoras del Parlamento Europeo desde 1999: debate institucional comunitario. 2. Protección jurídica en España. 2.1. La calificación jurídica del espacio radioeléctrico como un bien de dominio público. 2.2. Protección sanitaria en materia de radiocomunicaciones: la regulación jurídica estatal: el RD 1066/2001, de 28 de septiembre. 2.3. Breve referencia a la normativa autonómica. 2.4. Breve referencia a la normativa local. III. Bibliografía.

\section{INTRODUCCIÓN. RADIACIÓN NO IONIZANTE Y SALUD PÚBLICA}

\section{Preocupación social por los campos electromagnéticos}

En los últimos años, una serie de estudios científicos que señalan la peligrosidad de los campos electromagnéticos (CEM) han reavivado el debate institucional sobre la imposición de límites al geométrico desarrollo de tecnologías que multiplican la exposición de la población, tales como el Wi-Fi o la tecnología móvil de tercera generación (UMTS).

Particularmente, el importante estudio del grupo BIOINITIATIVE ${ }^{1}$ ha desencadenado pronunciamientos de la Agencia Europea del Medio Ambiente (AEMA) ${ }^{2}$ y del Parlamento Europeo ${ }^{3}$ avisando de que la regulación vigente no protege la salud de las

\footnotetext{
${ }^{1}$ Vid. BIOINITIATIVE. (2007). A Rationale for a Biologically-Based Public Exposure Standard for Electromagnetic Fields (ELF and RF). Recuperado el 1 de mayo de 2010 de http://www.bioinitiative.org.

${ }^{2}$ La AEMA reconoció el 17 de septiembre de 2007, que los riesgos de los campos electromagnéticos son comparables a los del amianto, el tabaco y la gasolina con plomo, y que la evidencia científica actual es suficiente para cuestionar las bases científicas de los límites vigentes, miles de veces demasiado altos. Vid. http://www.eea.europa.eu/highlights/radiation-risk-from-everyday-devices-assessed.

${ }^{3}$ El Parlamento llama a la aplicación del principio de precaución en el sector, a la atención de los colectivos más vulnerables de la población y a desmarcarse de la presión de grupos industriales y de
} 
personas y llamando a la implementación de una normativa de valores límite mucho más estricta que la actual, al tiempo que varios países han endurecido sus normativas ${ }^{4}$. Sin embargo, tanto la Comisión Europea como la Organización Mundial de la Salud (OMS) no han variado todavía su política, que data de hace doce años.

Esta situación ha generado un clima de preocupación y desinformación social que puede verse plasmado en el Eurobarómetro especial de la Comisión Europea sobre campos electromagnéticos, conforme al cual un $48 \%$ de la población de la unión se mostró muy preocupada o simplemente preocupada por los riesgos potenciales para la salud de los campos electromagnéticos ${ }^{5}$ y un $65 \%$ manifestó no estar satisfecho con la información recibida al respecto ${ }^{6}$ (cifra que en nuestro país se amplía al 70\% de la población ${ }^{7}$ ).

Esta preocupación ${ }^{8}$ está justificada, no sólo por la incertidumbre reinante respecto a la salubridad de estas radiaciones y la deficiente regulación jurídica ${ }^{9}$, sino también porque las mismas son impuestas a la población al margen de su consentimiento. Los campos electromagnéticos son ubicuos ${ }^{10}$ y resulta imposible vivir en nuestra sociedad sin ser

organizaciones regionales e internacionales (como la OMS). Vid. PARLAMENTO EUROPEO, Proposición de Resolución sobre las preocupaciones en cuanto a los efectos para la salud de los campos electromagnéticos. $2008 / 2211$ (INI).

4 Por ejemplo, Liechtenstein se ha convertido en el primer país en adoptar los valores límite recomendados por el estudio BIOINITIATIVE mediante una Ley que prevé reducir los actuales límites 10.000 veces para 2012. Así lo establece el art. 34.4 de la Ley sobre la protección del medio ambiente de 29 de mayo de 2008. Recopilación de las leyes federales $\mathrm{n}^{\circ} 199$ con fecha del 29 de mayo de 2008 , aplicable el 1 de septiembre de 2008.

${ }^{5}$ Vid. COMISIÓN EUROPEA, "Special Eurobarometer 272a / Wave 62.2 - TNS Opinion and Social. Fieldwork October-November 2006”, Bruselas, junio 2007, pp. 11-12.

${ }^{6}$ En España, ni el Gobierno ni los medios de comunicación nacionales informan sobre la existencia de ningún problema desde 2002.

${ }^{7}$ COMISIÓN EUROPEA., "Special Eurobarometer 272a ...” cit., pp. 14-15.

${ }^{8}$ En España, la alarma se desató en 2001 a raíz de la aparición de un conglomerado de casos de leucemia infantil en el colegio García Quintana de Valladolid, cercano a varias antenas. Este conglomerado de cáncer no es el único, y en los últimos ocho años es posible documentar solo en España al menos 100 más, que totalizan miles de casos de cáncer y de afecciones cardiovasculares u otras enfermedades relacionadas con la instalación de antenas en las proximidades. Para más información, consultar la web de la asociación vallisoletana de afectados por las antenas de telefonía, www.avaate.org.

${ }^{9}$ En noviembre de 2008, más de 50 organizaciones sociales y de vecinos pedían al Ministro de Industria, Miguel Sebastián, que endureciera la normativa sobre radiación no ionizante porque la actual no garantiza la salud. Vid. "Organizaciones sociales y vecinos urgen a Industria a modificar la regulación de la instalación de antenas de telefonía" (2008, 11 de noviembre). Recuperado el 1 de mayo de 2010 de: http://www.europapress.es/.

${ }^{10}$ Algunos autores han alegado que se trata del experimento biológico más grande jamás realizado. Vid. FIRSTENBERG, A. (2006, enero), "The largest biological experiment ever". Sun Monthly, enero de 2006. Recuperado el 1 de mayo de 2010 de www.sunmonthly.com/firstenberg.htm. 
irradiado día y noche y cada año a mayor potencia y desde un mayor número de terminales ${ }^{11}$.

Ante esta situación, la mayor parte de países de nuestro entorno han comenzado a actuar de una u otra forma. En Alemania, el Gobierno Federal recomienda a los ciudadanos no utilizar Wi-Fi ${ }^{12}$, En Reino Unido, recomienda desde el año 2000 que las llamadas sean lo más cortas posibles y que los menores de 16 utilicen el móvil sólo en emergencias ${ }^{13}$; también se plantea detener la expansión del Wi-Fi en las escuelas ${ }^{14}$. En abril de 2008, la Biblioteca Nacional de Francia, así como otras bibliotecas de París, retiraron el Wi-Fi sustituyéndolo por cable, a raíz de las conclusiones de un estudio científico de la Universidad de Chicago ${ }^{15}$ y recientemente el Gobierno francés ha anunciado la prohibición del uso de teléfonos móviles en la escuela primaria ${ }^{16}$.

Contrastando con este desarrollo, en España se introduce la ampliación del Wi-Fi en los programas electorales como una prioridad ${ }^{17}$ y el Gobierno diseña un plan de subvención a los Ayuntamientos para que autoricen la instalación de cuantas más antenas mejor ${ }^{18}$ la misma semana que el Parlamento Europeo llama a una normativa más limitadora.

\footnotetext{
${ }^{11}$ Así, la exposición a campos electromagnéticos en 2007 era del orden de 150 millones de veces mayor que treinta años atrás y continúa creciendo. Vid. PORTOLÉS, M., "Mentiras, estadísticas y telecomunicaciones", Levante, EMV, 17 de mayo de 2007. El número de aparatos con tecnología GSM es actualmente de unos 4.000 millones. Se advierte la enormidad de esta expansión si se tiene en cuenta que tan solo cuatro años antes, en 2006, había tan solo 1.500 millones, y hace 5 años 1000 millones.

12 Así se manifestó la Bundesamt für Strahlenschutz (Oficina federal para la protección frente a la radiación), en su respuesta ante el Parlamento de Baviera. Vid. Anhörung des Ausschusses für Umwelt und Verbraucherschutz des Bayerischen Landtages zum Thema "Einfluss des Mobilfunks auf die menschliche Befindlichkeit”, de 7 de diciembre de 2006. Esta opinión fue reiterada por el gobierno alemán en respuesta a una pregunta parlamentaria de diversos grupos verdes el 23 de julio de 2007 (Drucksache 16/6117 - Deutscher Bundestag - 16. Wahlperiode 23-07-2007).

${ }^{13}$ Vid. UK Department of Health. (2000). Mobile Phones and Health. Recuperado el 1 de mayo de 2010 de, www.doh.gov.uk/mobile.htm.

${ }^{14}$ Vid. "Suspend Wi-Fi in schools, says union chief following reports it causes ill-health", Daily Mail, 30 de agosto de 2008. Recuperado de la web del periódico: www.dailymail.co.uk.

${ }^{15} \mathrm{Vid}$. http://www.avaate.org/article.php3?id article=1260.

${ }^{16}$ Vid. "Francia prohibirá el uso de teléfonos móviles a los niños en la escuela primaria". El País, 27 de mayo de 2009.

${ }^{17}$ Por ejemplo, en el marco de las elecciones municipales madrileñas, Miguel SEBASTIÁN prometió extender una red gratuita de Wi-Fi por todo Madrid, incluyéndose 403 centros educativos y 79 centros de mayores, que son personas especialmente sensibles. El País, 2 de febrero de 2008.

${ }^{18}$ Se trata del Plan AvanzaDos del Ministerio de Industria. Vid. El País, 1 de septiembre de 2008.
} 


\section{Significado de la radiación y efectos sobre la salud.}

La radiación electromagnética existe en cualquier lugar y fenómeno del universo; todos los cuerpos, incluido el humano, emiten energía y tienen un campo magnético ${ }^{19}$.

La mayor parte de informes y documentos institucionales que niegan que la radiación pueda ser peligrosa comienzan con la siguiente frase: "los campos electromagnéticos ocurren en la naturaleza y por tanto siempre han estado presentes en la Tierra" ${ }^{\text {. }}$ Efectivamente, los campos electromagnéticos no solo son producidos por el hombre, sino que existen de forma natural en el Universo; de hecho, puede afirmarse que "son" el Universo ${ }^{21}$. Estamos sometidos, por ejemplo, a los rayos cósmicos, al campo magnético del Sol o al de la Tierra. Tales exposiciones, sin embargo, han sucedido a lo largo de muchos millones de años de evolución de la vida humana y fruto de ello es que ciertos ritmos geomagnéticos: las "resonancias Schumann" a las que vibra la superficie terrestre $(7,8 \mathrm{~Hz})$ coincidan con los arcos de frecuencias que utiliza nuestro cerebro.

No sucede lo mismo con la radiación artificial, a la que estamos sometidos masivamente desde hace apenas una generación. El Parlamento Europeo reconoce que "dado el tiempo relativamente escaso, durante el cual la humanidad se ha visto expuesta a ella, no tenemos ninguna inmunidad evolutiva ni contra los efectos nocivos que directamente pudiera tener sobre nuestros cuerpos, ni contra las posibles interferencias con los

\footnotetext{
${ }^{19}$ Esto fue postulado ya en 1845 por Michael FARADAY, descubridor de la inducción electromagnética. J.C. MAXWELL, que en la segunda mitad del siglo XIX sentó las bases matemáticas de la teoría del electromagnetismo, descubrió que el campo eléctrico genera un campo magnético y que el campo magnético genera uno eléctrico. Así pues, hablamos de campos "electromagnéticos".

${ }^{20}$ Esta comparación es recomendada por la OMS como técnica psicológica para reducir la percepción de riesgos en su documento "Estableciendo un diálogo sobre los riesgos electromagnéticos" (http://www.who.int/peh-emf/publications/risk_hand/es/index.html). Utilizan esta frase, por ejemplo, los siguientes informes: OMS. "Electromagnetic Fields and public health, The present evidence" (http://www.who.int/peh-emf/publications/en/); COMISIÓN EUROPEA., "Special Eurobarometer $272^{\mathrm{a}}$..." cit., p. 2. La frase es utilizada también en el marco de informes periciales tendentes a demostrar la inocuidad de los CEM no ionizantes. Por ejemplo, vid. HERNANDO GRANDE, A., "Exposición a campos electromagnéticos: características y restricciones para evitar perjuicios a la salud", RIGA, marzo de 2002, pp. 40-41.

21 Todo está compuesto de energía. La famosa ecuación de EINSTEIN, E=MC2, hace equivaler las magnitudes correspondientes a "materia" y "energía", de tal forma que, simplificándolo, la energía no es sino una forma de materia en movimiento, y la materia no es sino una forma de energía. Ya a mediados del siglo XIX, Michael FARADAY opinaba que la única realidad subyacente es el "campo".
} 
procesos electromagnéticos naturales" ${ }^{22}$. Además, las propiedades de la radiación varían con la frecuencia o longitud de onda ${ }^{23}$.

Que los CEM sean invisibles no quiere decir evidentemente que no existan o que sean más inocuos que las cosas que sí se ven. Por el contrario, la radiación es algo totalmente material; está asentada desde los inicios de la mecánica cuántica la llamada "dualidad onda-partícula" ${ }^{24}$. Así, la energía que se propaga mediante movimientos ondulatorios, también se está propagando en realidad en forma de electrones.

Al tratar los efectos de la radiación, se suele distinguir entre la radiación ionizante y la radiación no ionizante, y dentro de ésta última, entre los efectos térmicos y los efectos no térmicos. La incertidumbre científica existe exclusivamente sobre los efectos no térmicos, mientras que está claro que la radiación ionizante y la no ionizante a ciertas frecuencias son dañinas tanto para el ser humano como para el medio en el que vive en la medida en que producen un calentamiento molecular.

Se habla de radiación ionizante ${ }^{25}$ a partir de $10{ }^{17} \mathrm{~Hz}$. A menores frecuencias, tenemos la radiación óptica y los llamados "campos electromagnéticos" (entre 1 y $10^{12} \mathrm{~Hz}$ ), que son sobre los que versa este trabajo. Los efectos térmicos comienzan a manifestarse a una frecuencia de $300 \mathrm{MHz}$, por lo que los produce tanto la radiación ionizante como la no ionizante. Ninguna duda científica cabe respecto a la peligrosidad de la radiación ionizante y respecto de los efectos térmicos, y en general todos los países han implementado una regulación jurídica protectora frente a ellos. Ahora bien, la radiación no sólo calienta tejidos: desde hace años se vienen documentando una serie de efectos distintos sobre los sistemas vivos, efectos "no térmicos".

\footnotetext{
${ }^{22}$ Vid. PARLAMENTO EUROPEO - DIRECCIÓN GENERAL DE INVESTIGACIÓN (DIRECCIÓN A), Los efectos fisiológicos y medioambientales de la radiación electromagnética no ionizante. $\mathrm{PE}, \mathrm{n}^{\circ}$ 297.574, marzo de 2001 .

${ }^{23}$ Recuérdese que también es radiación la que volatilizó en un instante a más de cien mil personas en Hiroshima.

${ }^{24}$ La primera formulación de esta paradoja es del físico francés DE BROGLIE, en 1924.

${ }^{25}$ La radiación ionizante (rayos cósmicos, rayos gamma, rayos X...), produce iones a su paso por la materia (ionización) lo cual puede ocasionar un desplazamiento de los electrones de los átomos produciendo rotura de los enlaces moleculares y lesionando los tejidos y el ADN. Esto último puede ser causa de cáncer.
} 
Es kilométrica la lista de estudios que han sugerido o demostrado interacciones de la radiación con el cuerpo humano de carácter no térmico ${ }^{26}$. Hoy en día, el coordinador del programa comunitario de investigación sobre campos electromagnéticos REFLEX $^{27}$ reconoce que la existencia de los efectos no térmicos es una cuestión unánimemente aceptada por la comunidad científica ${ }^{28}$, recayendo la incertidumbre únicamente sobre el mecanismo causal que media entre la exposición a CEM y dichos efectos.

El estudio que más implicaciones ha tenido a nivel institucional comunitario ha sido el BIOINITIATIVE de agosto de $2007^{29}$, que arrojó resultados bastante concluyentes sobre la relación entre la radiación no ionizante a radiofrecuencias y el cáncer y otras enfermedades. Más recientemente, científicos del grupo BIOINITIATIVE han demostrado en varios estudios que el uso a largo plazo del teléfono móvil resulta más perjudicial que el consumo de cigarrillos, aumentando considerablemente el riesgo de tumores cerebrales ${ }^{30}$.

Pero es la electrosensibilidad (o electrohipersensibilidad: EHS) el fenómeno que con mayor justificación exige la implementación de medidas protectoras. Las personas que desarrollan EHS sufren de dolores, fatiga, cansancio, pérdida de memoria, palpitaciones, dificultad para respirar, insomnio, depresión y muchos más ${ }^{31}$. Estos efectos están totalmente acreditados, y la incertidumbre radica en la determinación del

${ }^{26}$ Sin ánimo exhaustivo, se detallan algunos recientes: vid. HUSS, A, SPOERRI, A, EGGER, M y RÖÖSLI, M., "Residence near power lines and mortality from neurodegenerative diseases: longitufinal study of the Swiss population", American Journal of Epidemiology, 5 de noviembre de 2008, EBERHARDT, J.L, et al., "Blood-brain barrier permeability and nerve cell damage in rat brain 14 and 28 days alter exposure to microwaves from GSM mobile phones", Electromagnetic Biology and Medicine, núm. 27, 2008, DRAPER, G., VINCENT, T., KROLL, M.E., SWANSON, J., "Childhood cancer in relation to distance from high voltage power lines in England and Wales: a case-control study", British Medical Journal, núm. 330, 2005, WILLIAMS, C., "Cellphones affect human cells without heating them", New Scientist, 2619, 30 de agosto de 2007.

${ }^{27}$ Acrónimo de "Risk Evaluation of Potential Environmental Hazards from Low Energy Electromagnetic Field (EMF) Exposure Using Sensitive in vitro Methods". El estudio REFLEX fue financiado por la Unión Europea en el marco del programa "Calidad de vida y gestión de recursos vivos. Acción clave n $\mathrm{n}^{\circ}$ : Medio Ambiente y Salud”. El estudio completo puede descargarse en http://www.verumfoundation.de/cgi-bin/content.cgi?id=euprojekte01.

${ }^{28}$ Así lo manifiestan Franz ADLKOFER y varios oncólogos y neurólogos en la Declaración de París de 23 de marzo de 2009 sobre campos electromagnéticos y salud. En línea: http://www.artac.info/static.php?op=Declaration23mars2009.txt\&npds=1.

29 BIOINITIATIVE. (2007) A Rationale for a Biologically-Based Public Exposure Standard for Electromagnetic Fields... cit.

${ }^{30}$ Vid. PAWL, R., "Cell phones more dangerous than cigarettes!”, Surgical Neurology, Vol 70, Issue 5, November 2008, pp. 445-446.

${ }^{31}$ Todos ellos recogidos, por ejemplo, por médicos alemanes en la declaración de Bamberg de 10 de julio de 2005. Disponible en http://www.avaate.org/article.php3?id_article=137. 
nexo causal con la radiación, nexo que la OMS señala proceder de problemas psicológicos $^{32}$. Sin embargo, aunque la relación causal no resulte evidente a la OMS, sí lo resulta a un creciente número de médicos que cada día tienen que atender un mayor número de electrosensibles ${ }^{33}$.

Conforme a las estadísticas, cada año son más las personas que sufren de EHS. Así, por ejemplo, en Suecia la incidencia ha pasado del 0,63\% de la población en 1995 al 9\% en 2004, y en Austria del 1,5\% en 1995 al 13.3\% en 2003. Según los científicos suecos Örjan HALLBERG y Gerd OBERFELD, si el crecimiento de la EHS continúa al ritmo actual, en 2017 lo sufrirá la mitad de la población mundial ${ }^{34}$.

Suecia es, de momento, el único país que cuenta con programas de ayuda a las personas electrosensibles ${ }^{35}$. Recientemente, el Parlamento Europeo ha recomendado a los Estados de la Unión implementar la avanzada política sueca ${ }^{36}$.

Los efectos no térmicos están presentes en cualquier rango de frecuencias y, dada su diferente naturaleza, no parecen poder ser controlados mediante los mismos límites a la

\footnotetext{
${ }^{32}$ En contra de toda lógica médica, la OMS recomienda expresamente no intentar reducir la exposición a CEM no ionizantes del electrosensible- Vid. OMS. Electromagnetic Fields and Public Health. www.who.int.
}

\begin{abstract}
${ }^{33}$ Así, por ejemplo, en Suiza, un $71 \%$ de los médicos opinan que la EHS está relacionada directamente con la exposición a intensidades incluso muy pequeñas de radiación. Vid. AUSFELD-HAFTER, B, MANSER, R, KEMPF, D, BRÄNDLI, I., Elektrosensibilität und Komplementärmedizin - Eine Fragebogenerhebung in schweizerischen Arztpraxen mit komplementärmedizinischem Diagnostik - und Therapieangebot, BUWAL-Bern Universität, Berna, julio 2005. En Irlanda, la IDEA (Irish Doctors' Environmental Association) considera demostrada claramente la relación entre los síntomas de la electrosensibilidad y la exposición a CEM. Vid. IDEA. Position on Electro-Magnetic Radiation, disponible en: http://www.ideaireland.org/emr.htm. En la Declaración de Bamberg, varios médicos alemanes aseguran que sus pacientes electrosensibles se recuperan una vez dejan de estar expuestos a fuentes de radiación. Vid. la Declaración de Bamberg de 10 de julio de 2005. http://www.avaate.org/article.php3?id article $=137$. Grados más fuertes de electrosensibilidad obligan a los damnificados a abandonar sus hogares contaminados por CEM no ionizantes y convertirse en "refugiados". Esto sucedía a finales de 2006, por ejemplo, en Oberammergau (Alemania) cuando se comenzó a probar la nueva tecnología de comunicaciones T-Mobile. Vid. Carta abierta a la canciller Angela MERKEL de 42 científicos y médicos alemanes, hecha en Bamberg, el 27 de noviembre de 2006. Disponible en: http://www.avaate.org/article.php3?id_article=534.

${ }^{34}$ Vid. HALLBERG, Ö, OBERFELD, G., "Letter to the Editor: Will we all become electrosensitive?", Electromagnetic Biology and Medicine, núm. 25, 2006. Naturalmente, los casos graves de Electrohipersensibilidad son menos que los de mera Electrosensibilidad. Conforme a la OMS, el $10 \%$. Vid. OMS. Electromagnetic Fields and Public Health. www.who.int.
\end{abstract}

35 Sobre la protectora regulación en el municipio de Estocolmo, vid. JOHANSSON, O., "Electrohypersensitivity: State-of-the-Art of a Functional Impairment", Electromagnetic Biology and Medicine, núm. 25, 2006.

${ }^{36}$ PARLAMENTO EUROPEO. (2 de abril de 2009), Resolución sobre las consideraciones sanitarias relacionadas con los campos electromagnéticos. 2008/2211(INI). Recuperado el 1 de mayo de 2010 de http://www.europarl.europa.eu/sides/getDoc.do?pubRef=-//EP//TEXT+TA+P6-TA-20090216+0+DOC+XML+V0//ES. 
densidad de potencia de emisión que se utilizan para prevenir frente a los efectos térmicos. Es por ello que numerosos científicos sugieren una política de valores límite decenas de miles de veces más estrictos que los actuales. En la Resolución de la Conferencia Internacional de Salzburgo sobre estaciones base de telecomunicaciones móviles $^{37}$ se recogió el principio ALATA (tan bajo como la técnica permita), reconociéndose que las estaciones de telefonía móvil y los mismos aparatos podrían emitir a una densidad de potencia menor ${ }^{38}$. Se han producido declaraciones en el mismo sentido en Roccaraso $(2000)^{39}$, Catania $(2002)^{40}$, Friburgo $(2002)^{41}$, Helsinki $(2005)^{42}$, Bamberg $(2005)^{43}$, Benevento $(2006)^{44}$, Bruselas $(2007)^{45}$, Venecia $(2007)^{46}$ y París $(2009)^{47}$, además de muchas cartas abiertas ${ }^{48}$, firmadas por médicos y científicos de

37 Resolución fruto de la Conferencia Internacional sobre "Emplazamiento de Infraestructuras de Telefonía Móvil, Ciencias Aplicadas y Salud Pública”, celebrada en Salzburgo (Austria) el 7 y el 8 de Junio de 2000. En España, la Declaración de Alcalá de Henares de 2002, recogió y defendió los estándares de la Conferencia de Salzburgo. Vid. Declaración sobre "Contaminación Electromagnética y Salud" hecha en Alcalá de Henares en abril de 2002.

${ }^{38}$ La densidad de potencia recomendada en la Conferencia y utilizada actualmente en la ciudad de Salzburgo $\left(0,1 \mu \mathrm{W} / \mathrm{cm}^{2}\right)$ es 4.500 veces inferior a la más estricta que prevé la normativa comunitaria.

${ }^{39}$ Resolución de Roccaraso de 4 de junio de 2000, fruto del Congreso sobre CEM y estándares de salud pública.

40 Declaración de Catania de 2002 fruto de la Conferencia Internacional sobre el Estado de la Investigación sobre Campos Electromagnéticos.

${ }^{41}$ Declaración de Friburgo de 9 de octubre de 2002, realizada por IGUMED (Asociación Interdisciplinar para la Medicina Ambiental).

42 Declaración de Helsinki, realizada por el EMF-team Finland el 1 de enero de 2005. Disponible en: http://www.avaate.org/IMG/pdf/Helsinki_Appeal_2005_R5_1_.pdf.

${ }^{43}$ La Declaración de Bamberg es una carta abierta de varios médicos alemanes al primer ministro de Baviera, hecha el 10 de julio de 2005. Disponible en http:/www.avaate.org/article.php3?id article=137.

44 Declaración de Benevento, fruto de la conferencia internacional "The precautionary EMF approach: Rationale, Legislation and Implementation", celebrada por ICEMS (Comisión Internacional para la seguridad electromagnética) en Benevento (Italia), del 22 al 24 de febrero de 2006, y firmada por 31 científicos internacionales.

${ }^{45}$ Llamamiento de Bruselas, de 31 de enero de 2007, redactado por la asociación Teslabel y por el grupo de trabajo Beperk-de-Straling y apoyado por un gran número de médicos y científicos belgas. Disponible en. http://www.avaate.org/IMG/pdf/LLAMAMIENTO_DE_BRUSELAS.pdf.

${ }^{46}$ Declaración de Venecia, promovida por ICEMS, tras el $6^{\circ}$ Taller ICEMS de 17 de Diciembre de 2007 y firmada por 46 científicos internacionales.

${ }^{47}$ Declaración de París de 23 de marzo de 2009 sobre campos electromagnéticos y salud. Disponible en: http://www.artac.info/static.php?op=Declaration23mars2009.txt\&npds=1.

48 Muchas de ellas en Alemania, el país del más rápido despliegue de infraestructuras de telecomunicaciones. Como la de Hof de 28 de mayo de 2005, firmada por 54 científicos; la de Lichtenfels, de 5 de julio de 2005, firmada por 31 científicos; la de Coburgo, firmada por 93 médicos; o la de Freienbacher, de 25 de septiembre de 2005, firmada por 53 médicos. Todas ellas disponibles en: http://www.next-up.org/main.php?param=nouvellesdumonde11\#3. 
todo el mundo que insisten en la abrumadora evidencia de los efectos no térmicos de la radiación no ionizante a todas las frecuencias.

Es posible hablar, por lo tanto, de dos fenómenos completamente distintos: efectos térmicos y efectos no térmicos. Frente a los segundos, como enseguida veremos, no se trata de que la protección jurídica sea insuficiente, sino de que no existe.

\section{REGULACIÓN JURÍDICO-SANITARIA DE LOS CAMPOS ELECTROMAGNÉTICOS}

En 1992 se constituyó la Comisión Internacional para la Protección Contra las Radiaciones No Ionizantes (ICNIRP ${ }^{49}$ ). Se trata de una organización no gubernamental reconocida por la OMS, la OIT y la Comisión Europea que ha establecido unos valores límite de exposición a radiación no ionizante (en general, $10 \mathrm{~W} / \mathrm{m}^{2}$ ) en sus Recomendaciones de $1998^{50}$ que se utilizan en gran cantidad de países incluido el nuestro $^{51}$. Por otro lado, en el año 1996 la OMS puso en marcha el Proyecto CEM, que tiene como objetivo reunir los conocimientos actuales y recursos disponibles de ciertos organismos internacionales y nacionales para preparar recomendaciones científicas respecto a la evaluación del riesgo sanitario de exposición a la radiación no ionizante. Ninguna de estas instituciones ha recomendado de momento la adopción de un enfoque precautorio frente a unos riesgos que, como hemos visto, han dejado de ser potencialidades hipotéticas para convertirse en daños actuales y efectivos.

\section{Protección jurídica en la Unión Europea}

Las instituciones comunitarias regulan los efectos de los CEM en tres ámbitos: la protección de la libre circulación de productos eléctricos y electrónicos (compatibilidad

\footnotetext{
49 International Comisión on Non-Ionizing Radation Protection.

${ }^{50}$ Se trata de las "Recomendaciones para limitar la exposición eléctricos, magnéticos y electromagnéticos (hasta $300 \mathrm{GHz}$ )" de ICNIRP (Comisión Internacional para la protección contra las radiaciones no ionizantes) de 1998. Estas recomendaciones fueron publicadas en la revista Health Physics, vol. 74, n 4, pp. 494-522.

51 Dichos valores límite son, fundamentalmente una densidad de potencia de $10 \mathrm{~W} / \mathrm{m}^{2}$ para infraestructuras que emitan entre 10 y $300 \mathrm{Ghz}$ (las bandas de frecuencia utilizadas por la telefonía móvil).
} 
electromagnética) ${ }^{52}$, la protección de la seguridad y salud de los trabajadores en el ámbito laboral ${ }^{53}$ y la protección del público en general. De ellas, es objeto de este trabajo únicamente la tercera.

La normativa que regula la protección del público en general, que se materializa en la Recomendación del Consejo de Ministros de Sanidad de la UE 1999/519/CE, de 12 de julio de 1999, es deficiente por muchas razones: en primer lugar no es vinculante, en segundo lugar no tiene en cuenta los efectos no térmicos ni arbitra ningún criterio de gestión de la incertidumbre, al consistir en una mera transposición de las Directrices de ICNIRP. Finalmente, se trata de una norma ineficaz, puesto que los límites que establece no son jamás superados por las instalaciones que regula.

La Unión Europea no ha sido ni es precursor mundial de la protección frente a los efectos negativos para la salud de las radiaciones no ionizantes ${ }^{54}$. Unos veinte años antes de que se iniciara la regulación comunitaria al respecto, la Unión Soviética ya disponía de normas de protección que continúan siendo del orden de 100 veces más estrictas que las vigentes en la Unión Europea ${ }^{55}$. Hoy en día, numerosos Estados, tanto comunitarios como no comunitarios, han establecido una normativa más estricta que la de la Recomendación de 1999 en uno u otro aspecto de la protección frente a la radiación. Así, y dentro de la propia Unión Europea, son casi la mitad: Reino Unido,

\footnotetext{
${ }^{52}$ La norma de referencia sería hoy la Directiva 2004/108/CE, del Parlamento europeo y del Consejo, de 15 de diciembre de 2004, relativa a la aproximación de las legislaciones de los Estados miembros en materia de compatibilidad electromagnética, pero el volumen y minuciosidad de la normativa comunitaria relativa a compatibilidad electromagnética supera con creces aquel de la normativa relativa a protección de la salud, de forma que cabe afirmar que, paradójicamente, el Derecho comunitario proporciona una mayor protección a la instrumentación electrónica que a los seres humanos. Así se afirma en el estudio de la Universidad de Warwick y del Instituto Internacional de Biofísica adjunto al dictamen del Parlamento Europeo: Los efectos fisiológicos y medioambientales de la radiación electromagnética no ionizante.

${ }^{53} \mathrm{Si}$ bien existe una extensa normativa al respecto, la norma que aborda la cuestión más directamente es la Directiva 2004/40/CE, de 29 de abril de 2004, sobre las disposiciones mínimas de seguridad y de salud relativas a la exposición de los trabajadores a los riesgos derivados de los agentes físicos (CEM).

${ }^{54}$ Esta situación sería "contraria a la voluntad de la Unión Europea, expresada en el V Programa de acción ambiental comunitaria, de encabezar el tránsito hacia el Desarrollo sostenible a escala mundial". Vid. SANTAMARÍA ARINAS, R.J., "Contaminación electromagnética y Derecho Ambiental. Las pautas de la política comunitaria y el modelo italiano", Revista Electrónica de Derecho Ambiental, núm. 8, Diciembre de 2002.

55 "No puede ser una coincidencia que en Rusia, donde se descubrió por primera vez hace 30 años la sensibilidad de frecuencia específica de los organismos vivos a la radiación de microondas de intensidad ultrabaja, las directrices de exposición (aun cuando se apliquen sólo en la teoría, y no en la práctica) todavía sean 100 veces más estrictas que las de la Comisión Internacional de Protección contra la Radiación No Ionizante". PARLAMENTO EUROPEO, Dirección General de Investigación (Dirección A)., Los efectos fisiológicos y medioambientales de la radiación electromagnética no ionizante. PE, $\mathrm{n}^{\circ}$ 297.574, marzo de 2001.
} 
Italia, Suecia, Finlandia, Bélgica, Holanda, Luxemburgo, Lituania, Bulgaria, Polonia y Grecia $^{56}$. Y fuera de la Unión pueden ser citados Suiza, Liechtenstein, Canadá, Australia, Israel, Nueva Zelanda, Rusia y China.

\subsection{La recomendación del Consejo 1999/519/CE, de 12 de julio de 1999}

Basándose en los niveles recomendados por las citadas directrices de ICNIRP, el Consejo de la UE aprobó la Recomendación del Consejo de Ministros de Sanidad de la Unión Europea 1999/519/CE, de 12 de julio de 1999, relativa a la exposición al público en general a CEM (0 Hz a $300 \mathrm{GHz})$. Esta norma no es vinculante y además sólo regula riesgos sobre los que existe consenso científico internacional: los de los efectos térmicos $^{57}$. Así, no hace uso del principio de precaución ni del ALARA $^{58}$, y ello por expresa decisión en la propuesta de texto de la Comisión ${ }^{59}$. En todo caso, permite que los Estados establezcan un nivel más alto de protección ${ }^{60}$,

El sistema que se utiliza en la Recomendación no se fundamenta en una limitación de emisiones, sino en una limitación de exposiciones. Así, se basa en restricciones básicas y niveles de referencia, de la siguiente manera: Las restricciones básicas se prevén en el Anexo II, y son diferentes dependiendo de la frecuencia. Se basan únicamente en los efectos comprobados (los térmicos) y consecuentemente asignan protagonismo a un método de medición, el $\mathrm{SAR}^{61}$, que está ideado para medir exclusivamente dichos efectos térmicos y no sirve de indicativo para prevenir frente a los efectos no térmicos. Los niveles de referencia se prevén en el Anexo III y sirven como criterio adicional, debido a la dificultad de medir las restricciones básicas, a efectos prácticos de evaluación de la exposición. Su respeto garantiza en todo caso el respeto de las

\footnotetext{
${ }^{56}$ Los datos proceden de la propia Comisión Europea. Vid. COMISIÓN EUROPEA. (1 de septiembre de 2008). Segundo Informe sobre la aplicación de la Recomendación del Consejo que limita la exposición del público en general a los campos electromagnéticos (o Hz a $300 \mathrm{GHz}$ ), COM (2008) 532 final. Recuperado el 1 de mayo de 2010 de: www.europa.eu.int.

${ }^{57}$ Rec. 1999/519/CE, Considerando n ${ }^{\circ} 10$.

58 "Tan bajo como sea posible".

${ }^{59}$ La aplicación del enfoque cautelar y del principio ALARA había sido recomendada por las enmiendas del Parlamento Europeo, basadas en el llamado "informe TAMINO", pero fue rechazada expresamente por la Comisión Europea en su COM (98) 268 final.

${ }^{60}$ Rec. 1999/519/CE, Considerando no 15 . Cuestión que no necesitaba preverse expresamente, puesto que ello se deriva tanto del principio de subsidiariedad como del carácter no vinculante de esta norma.

${ }^{61}$ Tasa de absorción específica. Sirve para medir efectos térmicos en frecuencias de $100 \mathrm{KHz}$ a $10 \mathrm{GHz}$.
} 
restricciones básicas. Los niveles de referencia se utilizan como valores promedio calculados espacialmente sobre toda la superficie del cuerpo del individuo expuesto, y por tanto no son apropiados para exposiciones locales, como la del teléfono móvil; en este supuesto es necesario acudir directamente a las restricciones básicas. Para las estaciones base de telefonía móvil, se fijan unos valores límite de $10 \mathrm{~W} / \mathrm{m}^{2}$.

\subsection{Las propuestas más protectoras del Parlamento Europeo desde 1999: debate institucional comunitario}

La Recomendación de 1999 fue criticada por no adoptar un enfoque precautorio y guiarse exclusivamente por los informes de ICNIRP ya desde el mismo proceso de su elaboración ${ }^{62}$, y estas críticas se han recrudecido en los últimos tiempos.

En 2001, el Parlamento Europeo emitió un dictamen sobre los efectos fisiológicos y medioambientales de los campos electromagnéticos ${ }^{63}$ en el que incluía un informe de la Universidad de Warwick y del Instituto Internacional de Biofísica. En él, se desaconsejaba la utilización de teléfonos móviles por los niños y se recomendaba la fijación de valores límite mucho más estrictos que en la Recomendación de 1999.

A principios de 2002, la Comisión publicó su primer Informe de ejecución de la Recomendación del Consejo 1999/519/CE ${ }^{64}$, reiterando que el balance final de la evidencia científica todavía no permitía demostrar la relación causa-efecto entre la radiación no ionizante y diferentes problemas de salud. La misma política sostuvo el Comité científico para los riesgos sanitarios emergentes y recientemente identificados (SCENIHR) en marzo de 2007, que continuó recomendando únicamente el fomento de la investigación y de la información al público, pero ninguna medida precautoria ${ }^{65}$.

\footnotetext{
${ }^{62}$ Vid. Resolución legislativa que contiene el dictamen del Parlamento Europeo sobre la propuesta de recomendación del Consejo relativa a la limitación de la exposición de los ciudadanos a los campos electromagnéticos $0 \mathrm{~Hz}-300 \mathrm{GHz}(\mathrm{COM}(98) 0268)$ (procedimiento de consulta), DO C 175 de 21 de mayo de 1999, p. 129.

63 PARLAMENTO EUROPEO., Los efectos fisiológicos y medioambientales de la radiación electromagnética no ionizante... cit.

${ }^{64}$ Vid. COMISIÓN EUROPEA. (2002). Informe sobre la aplicación de la Recomendación del Consejo que limita la exposición del público en general a los campos electromagnéticos (o $\mathrm{Hz}$ a $300 \mathrm{GHz}$ ). Recuperado el 1 de mayo de 2010 de http://www.mityc.es/Nivelesexposicion/Secciones/UEuropea/.

${ }^{65}$ Vid. SCENIHR. (2007, 16-21 de marzo). Posible effects of Electromagnetic Fields (EMF) on Human Health. Recuperado el 1 de mayo de 2010 de www.europa.eu.int.
} 
Poco después, en septiembre de 2007 y tras los resultados de la investigación del citado grupo BIOINITIATIVE, la AEMA llamó a una regulación mucho más estricta del sector, reconociendo que los actuales umbrales no protegen la salud del público. Ello no tuvo ninguna repercusión en la Comisión Europea, que, en su segundo Informe de ejecución de la Recomendación de $1999^{66}$, tampoco recomendó modificar el texto.

Tres días después de la emisión de este Informe, el Parlamento Europeo se pronunciaba apoyando la posición de la AEMA sobre la necesidad de una protección más estricta. Lo hizo por medio de la Resolución de 4 de septiembre de 2008, sobre la Revisión intermedia del Plan de Acción Europeo sobre Medio Ambiente y Salud ${ }^{67}$. En dicha Resolución, el Parlamento manifestó gran interés por el informe internacional BIOINITIATIVE, avisó sobre los riesgos de los CEM procedentes de telefonía móvil, inalámbrica, Wi-Fi-Wimax-Bluetooth y teléfonos de base fija DECT y consideró que los límites de exposición fijados por la Recomendación de 1999 están obsoletos al no tener en cuenta la evolución de las tecnologías de la información y la comunicación, las recomendaciones de la AEMA o las normas de emisión más exigentes adoptadas en algunos países y no abordar la cuestión de los grupos vulnerables como las mujeres embarazadas, los recién nacidos y los niños. En consecuencia, pidió al Consejo que endureciera su regulación sobre valores límite de exposición ${ }^{68}$.

El último pronunciamiento relevante del Parlamento Europeo ha sido su Resolución de 2 de abril de 2009, sobre las consideraciones sanitarias relacionadas con los campos electromagnéticos ${ }^{69}$. En ella, se insta a la Comisión a que revise el fundamento científico y la adecuación de los límites de la Recomendación de 1999, se reclama la imposición de un requisito de etiquetado relativo a la potencia de las emisiones y se hace un llamamiento a ICNIRP y a la OMS para que "se muestren más transparentes y abiertas al diálogo con todas las partes interesadas a la hora de fijar normas".

\footnotetext{
${ }^{66}$ COMISIÓN EUROPEA. Segundo Informe sobre la aplicación de la Recomendación del Consejo que limita la exposición del público en general a los campos electromagnéticos... cit.

${ }^{67}$ PARLAMENTO EUROPEO. Resolución sobre la Revisión intermedia del Plan de Acción Europeo sobre Medio Ambiente y Salud... cit.

${ }^{68}$ El Parlamento también reconoció, en general, la escasa utilización del principio de precaución en las políticas comunitarias y el debilitamiento de la legislación existente bajo la presión de grupos de interés o de organizaciones regionales o internacionales, refiriéndose implícitamente a la lamentable labor de la OMS en el sector.

${ }^{69}$ Vid. PARLAMENTO EUROPEO. (2009, 2 de abril), Resolución sobre las consideraciones sanitarias relacionadas con los campos electromagnéticos. 2008/2211(INI). Recuperado el 1 de mayo de 2010 de http://www.europarl.europa.eu/sides/getDoc.do?pubRef=-//EP//TEXT+TA+P6-TA-2009$\underline{0216+0+\mathrm{DOC}+\mathrm{XML}+\mathrm{V} 0 / / \mathrm{ES} .}$.
} 


\section{Protección jurídica en España}

La radiación es eminentemente multidisciplinar; al igual que puede estudiarse científicamente desde diversas disciplinas como la física, la medicina, la biología, la química y la ingeniería, incide en diversos aspectos de nuestro ordenamiento jurídico, particularmente en el Derecho constitucional (afectando a diversos derechos y derechos fundamentales recogidos en nuestra Constitución), el Derecho civil (especialmente en materia de derecho de inmisiones y relaciones de vecindad) y el Derecho administrativo (sanitario, medioambiental, urbanístico, eléctrico y de radiocomunicaciones).

En el presente trabajo se abordará únicamente -y de forma resumida- la perspectiva administrativa ${ }^{70}$ y dentro de la misma, se centrará la problemática en las instalaciones de radiocomunicaciones (antenas de telefonía móvil), y ello por varias razones: en primer lugar, son una de las fuentes más importantes y en más rápido crecimiento de exposición de la población a campos electromagnéticos; en segundo lugar, se trata de una exposición impuesta a la población ${ }^{71}$. Finalmente, el Derecho de radiocomunicaciones es el único ámbito jurídico en el que existe una normativa limitadora de las emisiones con fundamentos sanitarios.

\subsection{La calificación jurídica del espacio radioeléctrico como un bien de dominio público}

La radiocomunicación consiste en la emisión de información a través de ondas electromagnéticas de radiofrecuencia que se desplazan a la velocidad de la luz a través del espacio. Dicho espacio cobra por tanto una importancia estratégica vital para la realización de las actividades de telecomunicaciones. Así, “desde la percepción de que el espacio libre consiente esta utilidad, se irá decantando la presencia y existencia de un recurso, en tanto que fuente u origen de un aprovechamiento o de un bien",72.

\footnotetext{
${ }^{70}$ Para un estudio sobre el resto con amplia bibliografía, Vid. EMBID TELLO, A.E., Precaución y Derecho. El caso de los campos electromagnéticos, Iustel, Madrid, 2010.

${ }^{71}$ A diferencia de otras como la de electrodomésticos, teléfonos portátiles (DECT), teléfonos móviles y redes Wi-Fi particulares, que hasta cierto punto se halla sujeta a la autonomía de la voluntad del usuario.

${ }^{72}$ Vid. HORGUÉ BAENA, C., "El espectro radioeléctrico. Delimitación conceptual y calificación jurídica en el derecho español", Justicia Administrativa, número extraordinario sobre propiedades públicas, 2006, p. $207 \mathrm{ss}$.
} 
La necesidad de una intensa intervención pública en la radiocomunicación surge del hecho de que el espacio radioeléctrico es un recurso limitado ${ }^{73}$, aunque en realidad, lo limitado no es el espacio radioeléctrico, dado que siempre es posible para cualquier usuario emitir a cualquier frecuencia, sino su utilidad, dado que la emisión de información dentro de una misma banda de frecuencias puede dar lugar a interferencias que impidan la radiocomunicación. Así, como indica FERNANDO PABLO, lo que el Estado persigue al prever el espacio radioeléctrico como un bien de dominio público es una utilización racional, eficaz y económica del mismo, que necesariamente implicará la exclusión relativa de su uso en determinadas circunstancias ${ }^{74}$.

La Ley General de Telecomunicaciones de 2003 (LGT) ${ }^{75}$ prevé un dominio público radioeléctrico (DPR) estatal y centra su objeto (siguiendo la terminología comunitaria ${ }^{76}$ ) en el "espectro radioeléctrico". Éste se define en el Anexo II de la LGT como "las ondas radioeléctricas en las frecuencias comprendidas entre 9 kHz y $3.000 \mathrm{GHz}$ ”. Sin embargo, el Reglamento de desarrollo de la LGT en lo relativo al uso del dominio público radioeléctrico (RUDPR) ha regresado a la antigua expresión de "espacio radioeléctrico" $" 77$, definiéndose éste como aquel por el que puedan propagarse ondas por debajo de los $3.000 \mathrm{GHz}$ sin guía artificial. Así pues, existe actualmente una contradicción dentro de la normativa vigente sobre si el DPR se constituye sobre el “espectro" o sobre el "espacio" radioeléctrico ${ }^{78}$.

\footnotetext{
${ }^{73}$ Las ondas radioeléctricas se hallan restringidas jurídicamente a aquellas inferiores a los 3.000 Ghz (Así lo establece el Convenio de la UIT, Anexo 1005, nota 101, así como en nuestro país, el actual art. 3 RUDPR); si bien hoy en día la tecnología solo permite un aprovechamiento comercial para radiocomunicación de un espectro entre los $9 \mathrm{KHz}$ y los $90 \mathrm{GHz}$ aproximadamente y además no todas las frecuencias sirven indistintamente a cualquier servicio de radiocomunicación.

${ }^{74}$ Vid. FERNANDO PABLO, M.M., "Sobre el dominio público radioeléctrico: espejismo y realidad", $R A P$, núm. 143, mayo-agosto 1997, p. 136.

${ }^{75}$ Ley 32/2003, de 3 de noviembre, General de Telecomunicaciones. (BOE núm. 264, de 4 de noviembre de 2003).

${ }^{76}$ Plasmada en la Decisión del Parlamento Europeo y del Consejo 676/2002/CE, de 7 de marzo, sobre un marco regulador de la política del espectro radioeléctrico en la Comunidad Europea.

77 Art. 3 Real Decreto 863/2008, de 23 de mayo, por el que se aprueba el Reglamento de desarrollo de la Ley 32/2003, de 3 de noviembre, General de Telecomunicaciones, en lo relativo al uso del dominio público radioeléctrico.

78 Otras legislaciones, como la francesa, se han ahorrado inteligentemente hacer referencia directa a aquello que constituye dominio público, mencionando únicamente lo que se considera una ocupación del mismo (la utilización de las frecuencias). Así, la Ley francesa 86-1067 de 30 de septiembre de 1986, relativa a la libertad de comunicación, establece en su art. 22 que "la utilización por los titulares de una autorización de frecuencias radioeléctricas disponibles en el territorio de la República constituye un modo de ocupación privativa del dominio público del Estado".
} 
El concepto de espectro radioeléctrico no se halla unánimemente fijado y no queda claro si se refiere al "conjunto de frecuencias" (lo que equivaldría a definirlo como un "mapa de distribución de las ondas") o al "conjunto de ondas a distintas frecuencias". Las ondas radioeléctricas se crean artificialmente, por lo que no pueden ser demanio natural, y tampoco pueden ser demanio por afectación, al no concurrir en ellas ninguna de las vinculaciones necesarias al uso público, servicio público o fomento de la riqueza nacional; tal vinculación se da a través de su utilización específica: a través de la información que se pretende transmitir a través de ellas ${ }^{79}$.

Por otro lado, la concepción del DPR sobre el "espacio radioeléctrico" tiene el problema de que el "espacio radioeléctrico" no existe, puesto que las ondas no requieren de sustancia alguna para propagarse. La única solución es entender que el DPR se proyecta sobre el "espacio físico", pero entonces tenemos que el Estado se estaría, en realidad, arrogando titularidad sobre "todo", y afectándolo todo a la eficacia en las radiocomunicaciones. La consecuencia de ello es lógica: una merma en la salud de la población, que no solo vive “dentro de”, sino que, más aún, “es” el DPR. La solución también es lógica: la afectación del DPR a finalidades sanitarias y/o ambientales, lo cual es compatible con la técnica del demanio público tal y como han establecido la doctrina $^{80}$ y la jurisprudencia constitucional ${ }^{81}$. Como se explicará enseguida, ya existen condiciones sanitarias a las licencias de uso del DPR, si bien resultan insuficientes.

La doctrina ha señalado también otros problemas de compatibilidad de la técnica del dominio público con la radiocomunicación ${ }^{82}$, y parte de ella ha defendido consecuentemente la utilización de otras técnicas disponibles, como la reserva de recursos esenciales del art. 128.2 CE, posibilidad que GARCÍA DE ENTERRÍA y FERNANDO PABLO defienden como más adecuada ${ }^{83}$. De esta forma, de aplicarse éste

\footnotetext{
${ }^{79}$ Vid. MOLINA GIMÉNEZ, A., Las Antenas de Telefonía Móvil. Régimen Jurídico, Aranzadi. Navarra, 2002, p. 59.

${ }^{80}$ Por ejemplo, vid. GARCÍA VITORIA, I., Prohibiciones ambientales y libertad de empresa, Lex Nova, Valladolid, 2004.

${ }^{81}$ En ese sentido, en la STC 227/1988, de 29 de noviembre, se menciona entre los fines de los bienes de dominio público aquellos vinculados a la satisfacción de necesidades colectivas primarias como la que garantiza el art. $45 \mathrm{CE}$ (derecho a un medio ambiente adecuado).

82 Es problemático, por ejemplo, predicar de la radiocomunicación las dos características propias del demanio público: la inembargabilidad y la inalienabilidad, que difícilmente se ajustan al espectro o espacio radioeléctrico al no se este un objeto apropiable.

${ }^{83}$ Vid. GARCÍA DE ENTERRÍA, E., La Ejecución autonómica de la legislación del Estado, Civitas, Madrid, 1984, p. 125, o también FERNANDO PABLO, M.M., "Sobre el dominio público radioeléctrico:
} 
régimen a la utilización de las frecuencias, se ahorraría toda la problemática relativa a la constitución de una titularidad estatal sobre el vacío, y se conseguiría del mismo modo la finalidad de exclusión de usos con el fin de garantizar la eficacia del servicio público.

Como conclusión, es posible advertir que el DPR no es un régimen demanial "al uso", ya que en realidad se está estableciendo sobre una actividad (la radiocomunicación), y no sobre un bien propiamente dicho. Sin embargo, no puede negarse que a pesar de todos los problemas conceptuales que genera, la técnica resulta eficaz a sus fines. En ese sentido, el DPR no sería sino un instrumento jurídico capaz de sustentar un conjunto de potestades públicas dirigidas a garantizar determinadas finalidades de interés público ${ }^{84}$, entre ellas, como a continuación se explica, la protección de la salud pública.

\subsection{Protección sanitaria en materia de radiocomunicaciones: la regulación jurídica} estatal: el RD 1066/2001, de 28 de septiembre

La LGT de 2003 prevé un desarrollo reglamentario sanitario de los niveles de emisión radioeléctrica en su art. 44.1.a). Esto se llevó a cabo (respecto de la LGT del 98) mediante el RD 1066/2001, de 18 de septiembre, por el que se aprueba el Reglamento que establece condiciones de protección del DPR, restricciones a las emisiones radioeléctricas y medidas de protección sanitaria frente a emisiones radioeléctricas $(\text { RPSER })^{85}$.

El RPSER es una copia de la Recomendación del Consejo de 1999 y, por lo tanto, de las directrices de ICNIRP, por lo que sigue el sistema de restricciones básicas y niveles de referencia que acaba de ser comentado. Los valores límite para emisiones de alta frecuencia (entre 10 y $300 \mathrm{Ghz}$ ), que es la utilizada por la telefonía móvil, se fijan en 10 $\mathrm{W} / \mathrm{m}^{2}$, es decir, 10.000 veces por encima de los valores recomendados, por ejemplo, por

espejismo y realidad..." cit, p. 132ss. La jurisprudencia y la doctrina han señalado en numerosas ocasiones que tal reserva de recursos no implica necesariamente la demanialización del bien, que puede permanecer sin titularidad alguna, sino tan sólo la reserva al Estado de la potestad para conferir derechos exclusivos de uso. Así el Tribunal Constitucional ha afirmado en su STC 227/88 que "reserva de recursos y demanialización no son equivalentes, cabe reserva sin incorporación al demanio y, viceversa, dominio público sin reserva de uso del bien demanial". La misma posición sigue CASSESE. Vid., en este sentido, CASSESE, S., I Beni pubblici, Giuffrè, Milano, 1969, p. 156. Para una posición contraria vid. CHINCHILLA MARÍN, C., La radiotelevisión como servicio público esencial, Tecnos, Madrid, 1988, p. 129.

${ }^{84}$ HORGUÉ BAENA, C., "El espectro radioeléctrico. Delimitación conceptual y calificación jurídica en el derecho español..." cit, p. 234.

${ }^{85}$ BOE núm. 234, de 29 de septiembre de 2001, y posteriores correcciones de errores en: BOE núm. 257, de 28 de octubre de 2001, y BOE núm. 93, de 18 de abril de 2002. 
la citada Conferencia de Salzburgo $\left(0,001 \mathrm{~W} / \mathrm{m}^{2}\right)$; teniendo como objeto únicamente los comprobados efectos térmicos de la radiación no ionizante.

Sin embargo, el RPSER no es una copia exacta de la normativa comunitaria, ya que deja fuera de su ámbito de aplicación las infraestructuras eléctricas ${ }^{86}$, a resultas de lo cual España carece de protección sanitaria en materia de electricidad incluso frente a peligros $\operatorname{comprobados}^{87}$. También parece excluir el RPSER de su ámbito de aplicación las instalaciones en suelo no urbano, como ha señalado algún autor ${ }^{88}$.

Esto contrasta con el tenor de otras regulaciones europeas, como, por ejemplo, la italiana, en la que el ámbito de aplicación de la norma dedicada a la protección frente a las radiaciones no ionizantes engloba cualquier fuente que pueda comportar la exposición de los trabajadores y de la población a campos electromagnéticos de frecuencias entre $0 \mathrm{~Hz}$ y $300 \mathrm{GHz}^{89}$ o la alemana que, más humildemente, pero desde hace mucho más tiempo (1996), establece valores límite para las infraestructuras de generación y transporte de energía eléctrica a $50 \mathrm{~Hz}^{90}$.

El fundamento jurídico del contenido del RPSER también difiere de aquel de la recomendación comunitaria de 1999. Así, mientras ésta tenía un fundamento exclusivamente sanitario, conforme a la disposición final $2^{\mathrm{a}}$ del RPSER, éste tiene un

\begin{abstract}
${ }^{86}$ El art. 2 RPSER establece que "Las disposiciones de este Reglamento se aplican a las emisiones de energía en forma de ondas electromagnéticas, que se propagan por el espacio sin guía artificial, y que sean producidas por estaciones radioeléctricas de radiocomunicaciones o recibidas por estaciones del servicio de radioastronomía". Ello parece excluir la radiación procedente de infraestructuras eléctricas. Sin embargo, el Anexo II de la misma norma establece niveles de exposición a FEB (frecuencias extremadamente bajas), propias únicamente de las instalaciones de de producción, transporte y distribución de energía eléctrica, DOMENECH PASCUAL considera que no parece plausible que el Anexo II colme la anterior laguna. Vid. DOMÉNECH PASCUAL, G., "La deficiente regulación del riesgo electromagnético creado por las instalaciones eléctricas", RADA, núm. 6, 2004, p. 102. El Parlamento Europeo opina lo mismo en su informe sobre la aplicación nacional de la Recomendación del Consejo de 12 de julio de 1999. PARLAMENTO EUROPEO, Los efectos fisiológicos ... cit, punto 7.9.13.

${ }^{87}$ En la práctica, sin embargo, se tienen en ocasiones por establecidos los valores límite del RPSER para campos de corriente alterna de $50 \mathrm{~Hz}$ y otras frecuencias procedentes de transformadores eléctricos y líneas de alta tensión, por ejemplo en la evaluación ambiental de planes generales. Vid. Estudio de contaminación electromagnética, incluido en la fase de aprobación inicial del plan general de Guadarrama, mayo de 2006, Evaluación Ambiental, S.L.C.I.F. B-19189331. Registro mercantil de Guadalajara, Tomo 318, Folio 38, Sección 8, Hoja GU-3238.
\end{abstract}

${ }^{88} \mathrm{Vid}$. SANTAMARÍA ARINAS, R.J., "La normativa estatal sobre campos electromagnéticos generados por estaciones radioeléctricas", RADA, núm. 2, 2003, p. 97.

${ }^{89}$ Aunque existen ciertas modulaciones respecto a las actividades de policía y de transporte público. Art. 2.1 de la Legge quadro de 22 de febrero de 2001, n. 36, sobre la protección de las exposiciones a campos eléctricos, magnéticos y electromagnéticos. Gacetta Ufficiale, núm. 55, del 7 de marzo de 2001.

${ }^{90}$ Sechsundzwanzigste Verordnung zur Durchführung des Bundes-Immissionsschutzgesetzes (Verordnung über elektromagnetische Felder - 26. BImSchV), de 16 de diciembre de 1996, Anexo II. 
doble fundamento, técnico y sanitario. Así, desarrolla por un lado la LGT al amparo del art. 149.1.21 ${ }^{\mathrm{a}} \mathrm{CE}$, y por otro la LGS, al amparo del art. 149.1.16 $\mathrm{CE}$; como enseguida veremos, se asigna fundamento técnico a artículos claramente sanitarios, lo cual ha granjeado a esta norma numerosas críticas.

Las normas sanitarias del RPSER tienen carácter de mínimos. Esto es deducible del carácter básico que para esta regulación fija la disposición final $2^{\mathrm{a}}$ de la misma norma ${ }^{91}$. Por otro lado, este carácter de mínimos de la regulación es evidente desde el momento en el que se reconoce que las emisiones normales de las estaciones de radiocomunicación al público en nuestro país están de media 1000 veces -y en ocasiones incluso 40.000 veces- por debajo de los valores límite recomendados ${ }^{92}$, hasta tal punto que puede afirmarse que RPSER, en lo tocante a sus valores límite, es una norma completamente inútil.

Sin embargo, el RPSER contiene un catálogo de medidas sanitarias de protección más amplio. El art. 7 prevé un procedimiento de evaluación de riesgos sanitarios por emisiones radioeléctricas, que corresponde al Ministerio de Sanidad en coordinación con las CC.AA, aunque debe llevarse a cabo "en función de la evidencia científica disponible y de la información facilitada por el Ministerio de Ciencia y Tecnología" (hoy Secretaría de Estado de Telecomunicaciones y para la Sociedad de la Información) $)^{93}$. El Ministerio de Sanidad y Consumo debe adaptar los valores límite de exposición al progreso científico teniendo en cuenta el principio de precaución y las evaluaciones realizadas por organizaciones nacionales e internacionales. Hasta el momento, sin embargo, nada de esto se ha hecho.

El RPSER establece también ciertas condiciones sanitarias al uso del DPR. Las más importantes se hallan en el art. 8.7, que prevé una serie de criterios que los titulares de las instalaciones radioeléctricas deben tener en consideración a la hora de realizar la planificación. Se habla, entre otras cosas, de 1) Deber de minimización de los niveles de

\footnotetext{
${ }^{91}$ SSTC 32/1983, 42/1983 y 80/1984, por ejemplo.

92 Vid. MINISTERIO DE CIENCIA Y TECNOLOGÍA. (2003, abril). Informe sobre la exposición del público en general a las emisiones radioeléctricas de estaciones de radiocomunicación. Recuperado el 1 de mayo de 2010 de www.setsi.mcyt.es/movil/top_mov.htm. Además, "Numerosos informes de las propias operadoras de telecomunicaciones y entidades vinculadas al sector coinciden con esta valoración". Vid. VIDA FERNÁNDEZ, J., "El conflicto de competencias en la intervención pública sobre las instalaciones de radiocomunicaciones: una resolución precipitada", Derecho y nuevas tecnologías (monografía); Revista de la Facultad de Derecho de la Universidad de Granada, 3 a época, núm. 8, 2005, p. 328.

${ }^{93}$ Lo que parece cerrar las puertas a una evaluación sanitaria por parte de las CC.AA.
} 
exposición del público en general a las emisiones radioeléctricas manteniendo una adecuada calidad del servicio, y 4) Deber de minimizar, en la mayor medida posible, los niveles de emisión sobre espacios sensibles tales como escuelas, centros de salud, hospitales o parques públicos. Éstas son, sin duda, las previsiones sanitarias más importantes del RPSER, ya que la minimización de emisiones que persiguen no se halla vinculada a los laxos valores límite del Anexo II. La interpretación que se ha llevado a cabo de este artículo desde el derecho aplicable, sin embargo, parece sugerir que no existe un "deber" propiamente dicho, sino que la minimización se hallaría simplemente "justificada"94, pero el artículo 8.7.4 ${ }^{\circ}$ RPSER habla claramente de un deber de minimizar emisiones en la mayor medida posible, lo cual debería ser objeto de una interpretación muy distinta.

La Comisión Europea, en su Informe sobre la aplicación de la Recomendación del Consejo de $1999^{95}$, ha entendido que el art. 8.7 RPSER tiene un carácter vinculante en cuanto a la minimización de emisiones en espacios sensibles, a la instalación del sistema emisor evitando que la emisión incida sobre el propio edificio y a la señalización y vallado de las instalaciones ${ }^{96}$. Sin embargo, y sin duda conscientemente, la Comisión omite mencionar el otro requisito del art. 8 RPSER, que es el deber de minimización de las emisiones al público en general ${ }^{97}$. Claramente no hay ninguna razón jurídica para separar a éste de sus adyacentes asignándosele un valor jurídico distinto; el texto de la norma parece muy claro en este aspecto.

Así, creo que habría de entenderse que todas las prescripciones técnicas del artículo 8 RPSER, incluidos los criterios de su apartado $7^{\circ}$, son vinculantes y que forman parte del condicionamiento del otorgamiento de títulos de uso privativo del DPR, como se

\footnotetext{
${ }^{94}$ En la Orden CTE/23/2002, de 11 de enero, por la que se establecen condiciones para la presentación de determinados estudios y certificaciones por operadores de servicios de radiocomunicaciones (OCTE23), se prevé, en relación con el estudio técnico que los operadores deben incorporar al proyecto para la utilización del DPR, que "cuando en un entorno de 100 metros de las estaciones existan espacios considerados sensibles (guarderías, centros de educación infantil, primaria, centros de enseñanza obligatoria, centros de salud, hospitales, parques públicos y residencias o centros geriátricos), el estudio tendrá en consideración la presencia de dichos espacios, para lo que se justificará la minimización de los niveles de exposición sobre los mismos según lo previsto en el artículo 8.7 del Reglamento...”.

${ }^{95}$ COMISIÓN EUROPEA. Informe sobre la aplicación... cit.

${ }^{96}$ Así lo manifiesta en el punto 7.9.13, dedicado a la aplicación de la Recomendación del Consejo de 1999 en España, donde indica que el RPSER, además de seguir fielmente la norma comunitaria, proporciona protección especial para los "espacios sensibles".

${ }^{97}$ Dicho requisito no encaja en la ideología de la Comisión, que como se ha visto, coincide en todo con aquella manifestada por ICNIRP y por la OMS desde hace más de una década.
} 
desprende claramente del art. 20.4 RUDPR ${ }^{98}$, que condiciona la autorización de los emplazamientos de las estaciones fijas de radiocomunicación, "a lo establecido en el Real Decreto 1066/2001...”. Así, la Agencia Estatal de Radiocomunicaciones ${ }^{99}$ podría perfectamente no autorizar una instalación fundamentándose en una incorrecta valoración del deber de minimizar las emisiones en la medida de lo posible, o, en su caso, revocar un título habilitante ya existente fundamentándose en el art. 28.1.a) RUDPR, que alude, como causa de dicha revocación, al incumplimiento de las condiciones y requisitos técnicos aplicables al uso privativo del DPR, entre los cuales han de entenderse lógicamente incluidas las previsiones del RPSER.

Resulta evidente el contenido sanitario de estos trámites, pero el art. 8 se fundamenta en la competencia exclusiva de radiocomunicaciones estatal ${ }^{100}$. Se prevé que el Ministerio de Sanidad y Consumo tenga acceso a la información que le resulte necesaria sobre los niveles de exposición detallados en el estudio que debe realizar el operador, y asimismo, que las autoridades sanitarias de las Comunidades Autónomas sean informadas por el Ministerio cuando lo soliciten (art. 8.4 RPSER). Esto, sin embargo, a todas luces no basta para salvaguardar las competencias que las Comunidades Autónomas deberían ostentar en una materia sanitaria conforme al art. 149.1.16 ${ }^{\mathrm{a}} \mathrm{CE}$.

También prevé el RPSER un régimen de inspección para el control de los valores límite de exposición del Anexo II (art. 9), que es requisito para perfeccionar la concesión o autorización de uso privativo del DPR y que corre a cargo de la Agencia Estatal de Radiocomunicación, dado que el RPSER considera esta inspección como desarrollo de la competencia estatal de radiocomunicación. Obviamente, este artículo también es materialmente sanitario. Tanto en este caso como en el del art. 8, parece incoherente una atribución competencial exclusiva al Estado en materia de autorización e inspección de valores límite de exposición cuando, en principio, dichos valores pueden ser desarrollados por las CC.AA. en ejercicio de sus competencias sobre sanidad. Éstas carecerán, así, de cualquier mecanismo para controlar el cumplimiento de su propia normativa. Es por ello que la doctrina coincide en señalar que la disposición final

\footnotetext{
${ }^{98}$ Real Decreto 863/2008, de 23 de mayo, por el que se aprueba el Reglamento de desarrollo de la Ley 32/2003, de 3 de noviembre, General de Telecomunicaciones, en lo relativo al uso del dominio público radioeléctrico.

${ }^{99}$ Organismo previsto por la LGT de 2003, pero todavía no creado.

${ }^{100}$ Conforme a la disposición final $2^{\mathrm{a}}$ RPSER.
} 
segunda del RPSER es inconstitucional por no calificar como básicos los capítulos que afectan a las competencias autonómicas ejecutivas en materia de sanidad ${ }^{101}$.

Respecto a los municipios, que ni siquiera son mencionados en el RPSER, esta solución podría además vulnerar el art. 42.3 de la LGS, en cuanto que ésta incluye entre las responsabilidades mínimas de los ayuntamientos en relación al obligado cumplimiento de las normas y planes sanitarios el control sanitario del medio ambiente, de industrias, actividades y servicios, transportes, ruidos y vibraciones y de edificios y lugares de vivienda y convivencia humana. Conforme a DOMÉNECH PASCUAL, este precepto otorga una competencia municipal para la comprobación de que las instalaciones de radiocomunicación cumplen los requisitos sanitarios legalmente establecidos ${ }^{102}$.

En cumplimiento de la obligación impuesta por el art. 9.3 del RPSER, la Dirección General de Telecomunicaciones y Tecnologías de la Información (DGTTI) elaboró, en 2002, un plan de inspección para comprobar la adaptación de las instalaciones a lo dispuesto en el RPSER. Resultado de este plan es el Informe del Ministerio de Ciencia y Tecnología de abril de 2003 sobre la exposición del público en general a las emisiones radioeléctricas ${ }^{103}$. En este informe, el Ministerio constata que "todas las mediciones de niveles de emisiones radioeléctricas reflejadas en las certificaciones, así como los valores contrastados de las mismas, están muy por debajo de los valores de referencia que garantizan la salud para las personas según el RPSER”.

Por otro lado, y respondiendo a la previsión de la disposición adicional única del RPSER, el Ministerio de Sanidad y Consumo elaboró, en agosto de 2005, un informe sobre la aplicación del RPSER ${ }^{104}$, en el que se hace un sucinto recuento de la regulación

\footnotetext{
${ }^{101}$ SANTAMARÍA ARINAS, R.J., "La normativa estatal...” cit, p. 102. En el mismo sentido, vid. SANZ LARRUGA, F.J., La protección jurídica ante las radiaciones y la contaminación electromagnética (monografía), RADA, núm. 4, 2004, p. 169 y vid. TARDÍO PATO, J.A., "Instalaciones de Telefonía Móvil, salud y medio ambiente", RADA, núm. 3, 2003, p. 60.

102 Vid. DOMÉNECH PASCUAL, G., "El control Municipal de la Contaminación Electromagnética", ESTEVE PARDO, José (dir.), Derecho del Medio Ambiente y Administración Local, Fundación Democracia y Gobierno Local, Madrid, 2006, p. 620.

${ }^{103}$ MINISTERIO DE CIENCIA Y TECNOLOGÍA. Informe sobre la exposición del público... cit.

104 Vid. MINISTERIO DE SANIDAD Y CONSUMO. (2005, agosto). Informe sobre la aplicación del Real Decreto 1066/2001, de 28 de septiembre, por el que se aprueba el Reglamento que establece condiciones de protección del dominio público radioeléctrico, restricciones a las emisiones radioeléctricas y medidas de protección sanitaria frente a emisiones radioeléctricas. V2. Recuperado el 1 de mayo de 2010 de http://www.msc.es/ciudadanos/salud-AmbLaboral/docs.
} 
en nuestro país. Dicho informe se basa en otro de la propia industria (de $\mathrm{AETIC}^{105}$ ) para afirmar contundentemente que "Una de las conclusiones (...) es que no puede afirmarse que la exposición a CEM dentro de los límites establecidos en la Recomendación del Consejo de 1999 produzca efectos adversos para la salud humana y que su cumplimiento es suficiente para garantizar la protección de la población”. Dicha afirmación es falsa: la práctica totalidad de informes científicos existentes en el mundo sobre la materia reconocen, como mínimo, la existencia de incertidumbre científica sobre los efectos no térmicos y el Parlamento Europeo y la AEMA avisan de que la actual normativa está obsoleta y no basta para proteger a la población ${ }^{106}$.

La evaluación pública de los riesgos de los CEM en España, por tanto, es parcial y tremendamente insuficiente; no resiste una comparación con el tratamiento de la cuestión en otros países como Alemania, donde pese a haberse llegado a similares conclusiones sobre la vigencia de las directrices de ICNIRP, la cuestión es investigada por un organismo independiente, la Strahlenschutzkommission (SSK) ${ }^{107}$, adscrito al Ministerio de Medio Ambiente y con competencias para elaborar sus propias recomendaciones sobre la protección frente a la radiación ${ }^{108}$. En uno de sus múltiples y detallados informes ${ }^{109}$, la SSK han propuesto la adopción de medidas precautorias complementarias a la regulación vigente, como lo son el criterio ALATA para la minimización de emisiones tanto como sea posible, la obligación de detallar la información sobre las emisiones electromagnéticas de los productos y un fomento general de la información a los ciudadanos sobre las emisiones de las infraestructuras que se vayan a construir ${ }^{110}$.

\footnotetext{
105 Asociación de Empresas de Electrónica, Tecnologías de la Información y Telecomunicaciones de España.

106 Además, el informe del Ministerio de Sanidad ignora muchos cientos de estudios científicos y al menos siete Conferencias Internacionales sobre la necesidad de implementar el principio de precaución, comenzando por una en nuestro propio país: la de Alcalá de Henares de abril de 2002. Los estudios que el Ministerio de Sanidad y Consumo cita en su informe no alcanzan la veintena y son, en su práctica totalidad, anteriores a 2001.

${ }^{107}$ Comisión para la protección frente a las radiaciones.

108 La SSK, originariamente vinculada a los riesgos de la radiación nuclear, estudia hoy en día la radiación globalmente, publicando informes tanto sobre tratamientos médicos con radiación, como sobre riesgos, detallando estudios por temática. Todos sus informes son accesibles en: www.ssk.de.

${ }^{109}$ STRAHLENSCHUTZKOMMISSION. (2010, 1 de mayo). Grenzwerte und Vorsorgemaßnahmen zum Schutz der Bevölkerung vor elektromagnetischen Feldern. Recuperado el 1 de mayo de 2010 de http://www.ssk.de/werke/kurzinfo/2001/ssk0103.htm.

${ }^{110}$ Con fundamento en las recomendaciones del citado documento de la SSK, el Gobierno alemán puso en marcha en 2002 un programa de investigación de los riesgos de la tecnología móvil, el Deutsche
} 
Esta situación sería diametralmente contraria al principio de precaución, hoy un principio general del Derecho Comunitario que en casos de incertidumbre científica obliga a las autoridades públicas a realizar una evaluación del riesgo lo más completa posible antes de decidirse por un determinado curso de acción ${ }^{111}$.

Así pues, se puede concluir que el RPSER, que aparentemente establece límites a la exposición a radiofrecuencias, en la práctica no lo hace, legitimando por tanto los valores de exposición actuales. No ha habido esfuerzo alguno de promoción de la investigación nacional, y se han basado informes públicos directamente en informes de asociaciones industriales. Finalmente, se ha intentado bloquear el acceso a la regulación al resto de Administraciones nacionales (CC.AA. y EE.LL.), cuestión que como inmediatamente se expone, no ha sido lograda satisfactoriamente.

\subsection{Breve referencia a la normativa autonómica}

En primer lugar, cumple reconocer la existencia de competencias autonómicas en la materia. La posibilidad de una regulación autonómica más restrictiva es evidente desde el momento en el que las restricciones básicas y los niveles de referencia fijados por el RPSER son considerados por su disposición adicional $2^{\mathrm{a}}$ como normas básicas en materia de sanidad y, por lo tanto, susceptibles de desarrollo por la normativa autonómica en virtud del art. 149.1.16 CE y de una asentada jurisprudencia constitucional $^{112}$. Esa es, desde sus inicios, la posición del Tribunal Constitucional, quien interpretó, en su STC 32/1983, de 28 de abril, que la competencia de fijación de bases debe considerarse una competencia de fijación de "mínimos"113. A las mismas conclusiones cabe llegar respecto a la materia medioambiental ${ }^{114}$.

Mobilfunk-Forschungsprogramm (DMF), en el marco del cual se han llevado a cabo 54 proyectos sobre biología, epidemiología, dosimetría y comunicación del riesgo, cuyos resultados son también accesibles en línea: http://www.emf-forschungsprogramm.de/.

${ }^{111}$ STPI Pfizer Animal Health, de 11 de septiembre de 2002, T-13/99, pt. 160.

112 Sobre los criterios constitucionales definitorios de lo básico y las competencias de desarrollo y ejecución, Vid. MUÑOZ MACHADO, S., Tratado de Derecho Administrativo y Derecho Público General, Vol. III, Iustel, Madrid, 2009, pp. 304 y ss.

113 ، (...) y, por consiguiente, cualquier Comunidad Autónoma que posea competencia en materia sanitaria (...) puede establecer medidas de desarrollo legislativo y puede añadir, a los requisitos mínimos determinados con carácter general por el Estado, otros que entienda oportunos o especialmente adecuados". STC 32/1983 FJ 30.

114 Donde la Constitución es clara respecto a la posibilidad de que las CC.AA establezcan normas adicionales de protección (art. 149.1.23 $\mathrm{CE}$ ), además de las competencias de gestión que les corresponden en virtud del art. 148.1.9 $\mathrm{CE}$. Consecuentemente, el TC ha establecido respecto al medio 
El principal problema que tiene esta regulación es la protección de la competencia exclusiva del Estado en materia de radiocomunicación ex art. 149.1.21 ${ }^{\circ} \mathrm{CE}$, que podría verse afectada por las competencias autonómicas en materia de sanidad y medio ambiente. El art. 29 LGT dice que la normativa sanitaria o ambiental autonómica o municipal "deberá únicamente reconocer el derecho de ocupación del dominio público o la propiedad privada para el despliegue de las redes públicas de comunicaciones electrónicas, pero podrá imponer condiciones ambientales y sanitarias, así como de seguridad pública, defensa nacional y de ordenación urbana y territorial, de conformidad con el Derecho comunitario Europeo, y siempre respetando el principio de proporcionalidad"115.

Algunas CC.AA han dictado, con los fundamentos antes mencionados, una regulación específica con diversos requisitos adicionales de protección sanitaria y medioambiental frente a las emisiones procedentes de las instalaciones de radiocomunicación. El resto se rigen por el RPSER. Las que han regulado son Cataluña, Castilla-La Mancha, Castilla y León, Navarra y La Rioja, todas ellas entre 2001 y 2002, a raíz de los casos de leucemia en el colegio García Quintana de Valladolid.

En Cataluña rige el Decreto 148/2001, de 29 de mayo, de ordenación ambiental de las instalaciones de telefonía móvil y otras instalaciones de radiocomunicación ${ }^{116}$. La norma aumenta la protección respecto de la regulada en el RPSER únicamente en cuanto a los niveles de referencia y tan sólo entre $10 \mathrm{Mhz}$ y $300 \mathrm{Ghz}$. En dicho rango de frecuencias, los valores límite de emisión que fija el Anexo I del Decreto 148/2001 son aproximadamente el doble de restrictivos que los del RPSER $\left(4,5 \mathrm{~W} / \mathrm{m}^{2}\right.$, frente a los 10 $\mathrm{W} / \mathrm{m}^{2}$ del RPSER) lo que no es demasiado ${ }^{117}$. En el Anexo II se fijan además unas distancias mínimas de protección. Dichas distancias varían dependiendo de la potencia (a partir de una potencia de $100 \mathrm{~W}$ ), y que pueden ir desde los $10 \mathrm{~m}$ hasta los $250 \mathrm{~m}$ (para potencias de $1.000 .000 \mathrm{~W}$ ). Dentro de dichos radios no puede existir una zona

ambiente la misma doctrina que en materia de sanidad, por ejemplo en sus sentencias 170/1989, 102/1995 y 306/2000, pero como el RPSER no se fundamenta en la competencia ambiental, en principio no cabría dictar una regulación autonómica de desarrollo fundamentando ésta en las competencias de desarrollo de la legislación básica estatal en materia de medio ambiente.

${ }^{115}$ Al respecto, TARDÍO PATO, J.A., "Instalaciones de Telefonía Móvil, salud y medio ambiente... cit, p. 58.

${ }^{116}$ Diario Oficial de la Generalitat de Cataluña núm. 3404, de 7 de junio de 2001, modificado por el Decreto 281/2003, de 4 de noviembre, que no introduce modificaciones sustanciales.

${ }^{117}$ Se trata de limitaciones muy pequeñas como para tener algún efecto sobre las emisiones efectivas de las instalaciones de radiocomunicaciones existentes. 
abierta al uso continuado por las personas. Se trata, en principio, de la previsión más garantista de esta norma ${ }^{118}$. Por último, el art. 14 del Decreto catalán somete a las instalaciones de radiocomunicación a licencia ambiental a otorgar por el ayuntamiento, que deberá ejercer un control ambiental inicial y periódico sobre ellas.

En Castilla-La Mancha rige la Ley 8/2001, de 28 de junio, para la Ordenación de las instalaciones de radiocomunicación ${ }^{119}$. La Ley declara guiarse por los garantistas valores máximos de exposición al público que establecen las recomendaciones de Salzburgo del 7 y el 8 de junio de 2000; Sin embargo, ello no es así, salvo en lo referente a lugares sensibles. En su Anexo I, la Ley fija unos niveles de referencia prácticamente iguales que los del Decreto catalán $\left(4,5 \mathrm{~W} / \mathrm{m}^{2}\right)$, mientras que en el Anexo III, se prevén limitaciones específicas para las densidades de potencia en suelo urbano y en los espacios sensibles, aludiendo expresamente la Ley a la aplicación del principio de precaución. En suelo urbano, independientemente de la frecuencia de emisión, el nivel máximo permitido de exposición es de $0,1 \mathrm{~W} / \mathrm{m}^{2}$, es decir, 100 veces más restrictivo que el RPSER. Mientras tanto, en lugares sensibles ${ }^{120}$ se fija el valor precautorio recomendado en Salzburgo con carácter general: $0,001 \mathrm{~W} / \mathrm{m}^{2}, 10.000$ veces más restrictivo que la normativa estatal. Se trata éste último de un valor que sí es susceptible de limitar las emisiones de un alto porcentaje de las antenas de nuestro país. Además de la fijación de niveles máximos de referencia y de áreas de protección, la Ley manchega exige a los operadores la incorporación de las "mejoras tecnológicas que vayan apareciendo y contribuyan a reducir los niveles de emisión de los sistemas radiantes", además de minimizar el impacto ambiental y visual de las antenas (art. 7).

La Ley de Castilla-La Mancha fue objeto de recurso de inconstitucionalidad por el Gobierno $^{121}$ en 2002, fundamentándose en que está invadiendo la competencia

\footnotetext{
${ }^{118} \mathrm{Si}$ bien el alejamiento de las instalaciones no garantiza necesariamente un menor nivel de exposición de la población a la radiación, puesto que muchas veces el operador se verá obligado a emitir a una mayor potencia para poder garantizar la cobertura en zonas alejadas de su estación base.

${ }^{119}$ Diario Oficial de Castilla-La Mancha núm. 78, de 10 de julio de 2001. BOE núm. 227, de 21 de septiembre de 2001.

${ }^{120}$ La Ley entiende por lugares sensibles las escuelas infantiles y centro educativos, centros sanitarios, hospitales y geriátricos y residencias de ancianos.

${ }^{121}$ Se trata del Recurso de inconstitucionalidad número 2194/2002, promovido por el Presidente del Gobierno contra determinados preceptos de la Ley de las Cortes de Castilla-La Mancha 8/2001, de 28 de junio, de la Ordenación de Radiocomunicación en Castilla-La Mancha, admitido a trámite por el TC. Al tratarse de un recurso de inconstitucionalidad interpuesto por el Gobierno, era de aplicabilidad el art. 161.2 CE, conforme al cual, el recurso produce inmediatamente la suspensión de la disposición recurrida.
} 
exclusiva del Estado en materia de radiocomunicación. El recurso plantea que el urbanismo, ordenación territorial, salud y medio ambiente no pueden ser invocados como títulos de intervención. Es interesante que el Gobierno no haga referencia al aspecto más restrictivo de la Ley de Castilla-La Mancha, que es la fijación, en lugares sensibles, de unos niveles de referencia 10.000 veces más estrictos que la regulación estatal. Esto tiene importantes consecuencias para el orden de distribución de competencias entre el Estado y las Comunidades Autónomas, ya que "implícitamente se está reconociendo que no hay discusión sobre la posibilidad de adoptar medidas adicionales de protección medio-ambiental que condicionen el ejercicio de la competencia del Estado sobre las Telecomunicaciones"122.

Un poco más tarde, en Castilla y León se aprobó el Decreto 267/2001, de 29 de noviembre, relativo a la instalación de infraestructuras de radiocomunicaciones ${ }^{123}$. Los niveles de exposición que fija esta norma son, sin embargo, los mismos que los del RPSER, aunque se reducen en un $25 \%$ en los espacios sensibles, y se obliga a tener en cuenta todas las emisiones radioeléctricas provenientes de otras fuentes del entorno. La única novedad importante del Decreto está en su art. 3, que se considera a las infraestructuras de radiocomunicación actividades clasificadas y, por tanto, sometidas al régimen específico regulado por la Ley 11/2003, de 8 de abril, de Prevención Ambiental de Castilla y León ${ }^{124}$.

El Decreto de Castilla y León fue recurrido por el Gobierno ante el Orden Contenciosoadministrativo $^{125}$, y tras un fallo desfavorable, de nuevo ante el Tribunal Supremo ${ }^{126}$. En su Sentencia de 3 de abril de 2007, el TS desestimó el recurso entendiendo que las

Sin embargo, el Tribunal Constitucional decidió levantar dicha suspensión en octubre de 2002, mediante el auto 175/2002, de 1 de octubre de 2002.

${ }^{122}$ Vid. RODRÍGUEZ-CHAVES MIMBRERO, B., "El ámbito de regulación de la normativa municipal en materia de telefonía móvil”, RDU, Año XLII, núm. 242, junio de 2008, p. 180.

${ }^{123}$ Boletín Oficial de Castilla y León núm. 233, de 30 de noviembre de 2001. Puede decirse en éste supuesto lo mismo que se decía del Decreto catalán, al prever el Estatuto de Autonomía de la Comunidad Autónoma de Castilla y León que la normativa de desarrollo de competencias compartidas con el Estado (como es el caso) deba adoptar la forma de Ley.

${ }^{124}$ El art. 4.1 del Decreto 267/2001 prevé las autorizaciones que la instalación de radiocomunicación requerirá "sin perjuicio de otras autorizaciones e informes sectoriales que resulten procedentes". Así, se prevé una licencia urbanística, en suelo rústico una autorización excepcional de uso del suelo conforme a los dispuesto en la Ley 5/1999, de 8 de abril, de Urbanismo de Castilla y León, y una licencia de actividad y apertura de acuerdo con lo establecido en la Ley de Actividades Clasificadas de 1993, hoy derogada por la Ley de Prevención ambiental de 2003.

${ }^{125}$ Recurso contencioso-administrativo número 857/2002 contra el Decreto de la Junta de Castilla y León 267/2001, de 29 de noviembre, relativo a la instalación de infraestructuras de radiocomunicación.

${ }^{126}$ Recurso de casación número 10180/2003. 
exigencias del Decreto no impedían el funcionamiento de la actividad de telecomunicaciones autorizada por la Administración General del Estado ${ }^{127}$.

Al año siguiente, se dictó en Navarra la Ley Foral 10/2002 para la ordenación de las estaciones base de telecomunicación por ondas electromagnéticas no guiadas ${ }^{128}$. La exposición de motivos hace referencia al principio de precaución y en consecuencia establece niveles de referencia más exigentes que los del RPSER, aunque son inferiores a los que establecen el Decreto catalán y el manchego, ya que no prevén límites más exigentes para zonas sensibles. A raíz de la STS de 27 de diciembre de 2007, puede considerarse que las instalaciones radioeléctricas en Navarra se hallan también sometidas a licencia de actividades clasificadas ${ }^{129}$.

En el mismo año, en La Rioja se dictó el Decreto 40/2002, de 31 de julio, de ordenación de las instalaciones de radiocomunicaciones ${ }^{130}$. Los niveles de referencia que dicho Decreto fija son los mismos que en la regulación estatal, sin embargo, en el art. 4 se declara también las infraestructuras de radiocomunicación como actividad clasificada, aspecto que fue confirmado por el TS en su STS de 3 de abril de $2007^{131}$.

Así pues, a día de hoy y conforme al estado de la jurisprudencia, se permite a las Comunidades Autónomas una regulación de la instalación de infraestructuras de radiocomunicación fundamentada en los títulos competenciales autonómicos en las materias de sanidad, medio ambiente, ordenación del territorio y urbanismo. El único límite que dicha regulación debe respetar es no impedir el ejercicio de la competencia estatal de radiocomunicación, y a tales efectos, se considera que la fijación de niveles de exposición más estrictos o el sometimiento a licencia de actividades clasificadas no viola tal extremo.

\footnotetext{
${ }^{127}$ STS de 3 de abril de 2007, sala $3^{\mathrm{a}}$ (RJ 2007\1987), FJ $3^{\circ}$.

${ }^{128}$ Boletín Oficial de Navarra, núm. 58, de 13 de mayo de 2002.

${ }^{129}$ Sobre ello se pronuncia el TS en su Sentencia de 27 de diciembre de 2007, (RJ 2007\9167), en cuyo FJ $1^{\circ}$ c) se dice que: "siendo la actividad que nos ocupa susceptible de causar daños al medio ambiente, producir riesgos para las personas o bienes, ocasionar molestias o alterar las condiciones de salubridad, debe serle aplicable el régimen de licencias que es propio a este tipo de actividades".

${ }^{130}$ Boletín Oficial de La Rioja, núm. 99, de 15 de agosto de 2002.

${ }^{131}$ STS de 3 de abril de 2007, Sala $3^{\text {a }}$, (RJ 2007\1989).
} 


\subsection{Breve referencia a la normativa local}

Es este un tema muy complejo donde abundan las normas y la jurisprudencia, y por tanto es insusceptible de un tratamiento completo en el presente artículo, que se limitará a dar una idea muy general de las posibilidades de gestión municipal de los riesgos de las instalaciones de radiocomunicación ${ }^{132}$.

En primer lugar, es necesario indicar que no existe de momento acuerdo jurisdiccional sobre si los municipios pueden dictar normas adicionales de protección ambiental o sanitaria en materia de infraestructuras de telecomunicaciones. Existe jurisprudencia en contra; así, por ejemplo, en la STSJ de la Región de Murcia de 17 de noviembre, se dice que "debe entenderse que los Ayuntamientos no están investidos de la potestad para dictar normas adicionales de protección. (...). Salvo que exista una habilitación legal expresa que les confiera la posibilidad de establecer normas más rigurosas en el ámbito del municipio, su actuación deberá limitarse (...) a comprobar el respeto de los niveles de emisión radioeléctrica y distancias fijadas en la normativa estatal o, en su caso, autonómica"133. Otra parte de la jurisprudencia sí admite esta posibilidad; así, la STSJ de la C.A. de las Islas Baleares, de 22 de febrero (JUR 2006\119042), concluye que "los límites del RPSER no generan una obligación y un derecho a emitir con base en los mismos, cuando en realidad no son más que límites que no pueden ser superados, pero que pueden $\mathrm{y}$ deben ser inferiores si no es indispensable para establecer comunicaciones. En consecuencia, dichos límites sí pueden ser completados por otros más exigentes establecidos por las Autoridades que sean competentes en la materia, y la entidad local sí lo es" ${ }^{\prime 134}$.

Si bien el art. 44 a) LGT obliga a los municipios a respetar los límites fijados por la normativa estatal, los arts. 28 y 29 de la misma ley se refieren a la posibilidad de que los municipios establezcan restricciones ambientales y sanitarias a la ocupación del dominio público municipal o de la propiedad privada, necesarias para la efectividad de las licencias de funcionamiento, restricciones que, como hemos visto, tienen su límite en no poner trabas que impidan completamente dicha ocupación. Lo que parece derivarse de este articulado son dos limitaciones al ejercicio de competencias por parte

\footnotetext{
132 Esta idea se desarrolla en DOMÉNECH PASCUAL, "El control Municipal de la Contaminación Electromagnética" cit, y en EMBID TELLO, Precaución y Derecho... cit.

${ }^{133}$ STSJ de la Región de Murcia, de 17 de noviembre (RJCA 2007\362), FJ $3^{\circ}$.

${ }^{134}$ En un sentido similar, la STSJ de Andalucía, de 1 de marzo de 2006 (JUR 2006\172248), FJ $2^{\circ}$.
} 
de las CC.AA y los EE.LL: por un lado, la obligación municipal y autonómica de no permitir emisiones más elevadas que las delimitadas por la normativa estatal (art. 44 a), y por otro lado, la obligación de no establecer restricciones tales que impidan la ocupación del dominio público municipal para la instalación de infraestructuras de radiocomunicación (art. 29), ocupación a la que los operadores tienen un derecho preexistente (art. 28). Dentro de este margen, parece que los municipios podrían ejercer sus competencias de control sanitario y ambiental atribuidas con carácter general por el art. 42 LGS.

Los municipios españoles comenzaron a intervenir masivamente en el sector de las radiocomunicaciones a raíz del conglomerado de leucemia infantil en el colegio García Quintana de Valladolid, fundamentalmente por medio de ordenanzas municipales ${ }^{135}$. El desorden normativo que se produjo llevó a la Federación Española de Municipios y Provincias (FEMP), a aprobar un Modelo de Ordenanza reguladora de la instalación y funcionamiento de las infraestructuras radioeléctricas ${ }^{136}$. Este Modelo fue modificado en 2008, fruto de acuerdos de la FEMP con AETIC y las cuatro operadoras de telefonía móvil (no hubo participación de ningún otro sector social), dando como lugar un texto $^{137}$ que asume una posición distinta frente a los riesgos de la radiación: ya no hace referencia a la protección de espacios sensibles, elimina la infracción muy grave por instalación de infraestructuras sin licencia y evita cualquier referencia a los riesgos para la salud pública (evita incluso la mención de la palabra "salud" en todo su articulado). Así, el Modelo de Ordenanza reguladora de las instalaciones de Radiocomunicación de 2008 es finalmente incluso menos protector que el RPSER estatal ${ }^{138}$, pero no todos los municipios lo han seguido.

\footnotetext{
${ }^{135}$ El uso de la ordenanza (norma sectorial) en lugar del de planeamiento urbanístico (norma territorial) resulta preferible, puesto que las ordenanzas de radiocomunicaciones no pretenden únicamente regular los emplazamientos, sino que establecen condiciones y restricciones de carácter sectorial sobre los mismos. Al respecto, Vid. SIBINA TOMÁS, D., "Las ordenanzas municipales reguladoras de las instalaciones de radiocomunicación", Cuadernos de Derecho Local, núm. 0, 2002, p. 152.

${ }^{136}$ El primer modelo de ordenanza fue el "Modelo de Ordenanza Municipal Reguladora de la instalación y funcionamiento de infraestructuras radioeléctricas", de 14 de junio de 2002, y tuvo un amplio seguimiento por parte de los municipios españoles.

${ }^{137}$ Modelo de Ordenanza Municipal reguladora de las infraestructuras de radiocomunicación, elaborado por el grupo de trabajo del servicio de asesoramiento técnico e información (SATI) para el despliegue de infraestructuras de telefonía móvil. Aprobado por la Comisión Ejecutiva de la FEMP el 29 de abril de 2008. Disponible en: www.femp.es.

${ }^{138}$ Que sí prevé la minimización de emisiones en su art. 8.
} 
Existen múltiples fórmulas jurídicas a través de las cuales los municipios españoles han restringido la instalación de infraestructuras de radiocomunicación en su territorio.

La prestación de los servicios de telecomunicaciones requiere de una licencia estatal, que a partir de la LGT de 2003 (que elimina las antiguas licencias individuales) es únicamente la concesión de uso del DPR regulada en los arts. 45.2 LGT y 18 RUDPR. Sin embargo, los ayuntamientos también pueden exigir a las operadoras la obtención de varios tipos de licencia municipal con fundamento en sus competencias urbanísticas y ambientales.

En particular, los ayuntamientos exigen una licencia de obras y una licencia de funcionamiento a cualquier tipo de actividad que pretenda instalarse en el municipio. Pero dentro del procedimiento de obtención de la licencia de funcionamiento en relación con infraestructuras de radiocomunicación, muchos municipios han introducido ciertos trámites de carácter ambiental ${ }^{139}$. Una vez otorgada la licencia, muchas Ordenanzas prevén la posibilidad unilateral del Municipio de modificar sus condiciones por razones de interés público ${ }^{140}$.

Es exigible también una licencia de ocupación del dominio público municipal, en caso de que dicho dominio público vaya a ser ocupado. Respecto a la misma, el $\mathrm{TS}^{141}$ indica que los Ayuntamientos titulares del dominio público que va a resultar afectado no pueden denegar la licencia necesaria para dicha instalación de infraestructuras, dado que la explotación de los servicios de telecomunicaciones lleva aparejado el derecho de ocupación. Sin embargo, sí que pueden establecer restricciones a dicha ocupación orientadas a la preservación de los intereses municipales, siempre que dichas restricciones no sean absolutas o desproporcionadas ${ }^{142}$. En todo caso, como señala

\footnotetext{
${ }^{139}$ Por ejemplo, la Ordenanza municipal reguladora de las instalaciones de estaciones radioeléctricas en Granada, de 29 de Octubre de 2004 (BOP n 251), prevé una licencia municipal de funcionamiento condicionada en ciertos aspectos, como la suscripción de un seguro de responsabilidad civil y la elaboración un plano de localización con indicación de los impactos paisajísticos expresando la potencia máxima irradiada en todas las direcciones del diseño.

${ }^{140}$ Así, por ejemplo, la Ordenanza de Molina de Segura permite al Ayuntamiento "exigir en cualquier momento la modificación de la ubicación de las instalaciones o de cualquiera de sus elementos, siendo esta modificación obligatoria para la empresa autorizada”. Ordenanza de Molina de Segura reguladora de la instalación y funcionamiento de las infraestructuras radioeléctricas. Boletín Oficial de la Región de Murcia $\mathrm{n}^{\circ} 298$, de 28 de diciembre de 2007, art. 25.8.

${ }^{141}$ STS de 24 de enero de 2000 (RJ 2000\331).

${ }^{142}$ En el mismo sentido, las STS de 18 de junio de 2001 (RJ 2001\8744) y de 4 de julio de 2006, y las SSTSJ de la Comunidad Valenciana de 30 de julio de 2007 (RJCA 2008\25) o de Cataluña de 24 de febrero de 2006 (JUR 2007\225640).
} 
SIBINA TOMÁS, la autorización de ocupación del dominio público municipal tiene una relevancia mínima en materia de infraestructuras de radiocomunicación de telefonía móvil $^{143}$, al contrario que para las redes de telefonía por cables, que exigen por su propia naturaleza una ocupación efectiva del mismo.

También cabe el sometimiento de la actividad a la licencia de actividades clasificadas. La radiación no ionizante es susceptible de reconducirse al ámbito de aplicación del Reglamento de Actividades Molestas, Insalubres, Nocivas y Peligrosas (RAMINP) ${ }^{144}$, o a las normas autonómicas equivalentes. Pese a no hallarse tipificada específicamente en el Anexo de dicha norma, es jurisprudencia asentada del TS que la clasificación de una actividad viene determinada "por la misma naturaleza de la actividad conforme a las definiciones del art. 3"145. Así, los CEM sí podrían ser incluidos en la categoría de actividades insalubres, definidas en el art. 3 del siguiente modo: “... las que den lugar a desprendimiento o evacuación de productos que puedan resultar directa o indirectamente perjudiciales para la salud humana"146.

DOMÉNECH PASCUAL sintetiza las ventajas que sí tendría el sometimiento de las instalaciones productoras de CEM al régimen de licencia de actividades clasificadas indicando que "Este régimen constituye una relación jurídica de tracto sucesivo en cuyo marco el ciudadano está obligado a ir adaptando la instalación y su funcionamiento a las nuevas circunstancias jurídicas y fácticas existentes en cada momento. Y la Administración puede tomar las medidas necesarias para garantizar esa adaptación" ${ }^{147}$.

Respecto a las CC.AA, como hemos visto, el TS ha acreditado la posibilidad de incluir la instalación de infraestructuras de radiocomunicación como actividades clasificadas $^{148}$. Muchos municipios han introducido también este requisito a través de

\footnotetext{
${ }^{143}$ SIBINA TOMÁS, “Las ordenanzas municipales...” cit, p. 160.

${ }^{144}$ Aprobado por Decreto 2414/1961, de 30 de noviembre. (BOE de 7 de diciembre).

${ }^{145}$ SSTS de 24 de julio de 1998, de 25 de marzo de 1999 y de 4 de octubre de 2000.

${ }^{146}$ El punto central para calificar de insalubre una emisión de ondas electromagnéticas es la expresión “que puedan", que utiliza el artículo 3 del RAMINP, lo que permite incluir en el régimen del Reglamento actividades sobre cuyos efectos perjudiciales para la salud humana no existe todavía una certeza científica. En ese sentido, DOMÉNECH PASCUAL, "El control Municipal de la Contaminación Electromagnética" cit, p. 612. En todo caso, podrían ser consideradas como actividades molestas, teniendo en cuenta la electrosensibilidad.

${ }^{147}$ DOMÉNECH PASCUAL, “La deficiente regulación...”, p. 92.

${ }^{148}$ STS de 27 de diciembre de 2007, (RJ 2007\9167), FJ 1 1º, c).
} 
Ordenanzas municipales ${ }^{149}$. Una parte de los Tribunales de Justicia niega esta posibilidad $^{150}$, mientras que otra parte la apoya ${ }^{151}$. Sus argumentos no son jurídicos: el debate aquí es sobre los hechos, sobre la peligrosidad o no de los CEM. De un modo más moderado, el TS ha concretado la forma en la que la clasificación de las instalaciones de radiocomunicación se dirime entre las competencias municipales y las autonómicas indicando que existe un régimen distinto dependiendo de que la Comunidad Autónoma tenga normativa específica sobre actividades clasificadas o que no la tenga. Sólo en este segundo caso resultaría posible para los municipios exigir la licencia de actividades clasificadas ${ }^{152}$. La mayor parte de la doctrina ha apoyado la clasificación de la instalación de infraestructuras de telefonía móvil ${ }^{153}$.

Otra de las medidas adoptadas por los Ayuntamientos frente a los riesgos de los CEM, sobre todo en 2001 tras el caso del Colegio García Quintana de Valladolid, fue la suspensión del otorgamiento de licencias de instalación de antenas de telefonía móvil. Lo han hecho fundamentándose en la competencia urbanística. En el Derecho estatal, dicha posibilidad está recogida en el art. 117 del Reglamento de Planeamiento Urbanístico $(\mathrm{RP})^{154}$, norma a la que se acogieron los municipios de Comunidades Autónomas que todavía no tenían normativa propia ${ }^{155}$, haciendo uso el resto de las leyes urbanísticas autonómicas $^{156}$.

\footnotetext{
${ }^{149}$ Por ejemplo, la Ordenanza de Castro Urdiales, Boletín Oficial de Cantabria ${ }^{\mathbf{o}} 145$, de 30 de julio de 2002 , en cuyo art. 1.4 se define a las instalaciones de emisión de radiofrecuencias como actividades peligrosas conforme al art. 3 RAMINP.

${ }^{150}$ En ese sentido, la STSJ de Valencia, de 9 de junio de 2008, (JUR 2008\302390), (FJ $6^{\circ}$ ).

${ }^{151}$ Por ejemplo, la STSJ de Valencia, de 17 de marzo de 2003 (RJCA 2007, 264) o la STSJ de Cantabria de 17 de junio de 2003 (RJCA 2003\916), FJ $7^{\circ}$.

${ }^{152}$ STS de 11 de octubre de 2006 (RJ 2006\7659), (FJ $3^{\circ}$ ).

153 DOMÉNECH PASCUAL, "El control Municipal de la Contaminación Electromagnética" p. 635; SIBINA TOMÁS, "Las ordenanzas municipales..." cit, pp. 161-162; o HERRERA DEL REY, J.J., "Antenas y principio de precaución. La imprescindible exigencia de licencia de actividad previa a su instalación”, La Ley, núm. 2, 2006, p. 3.

${ }^{154}$ Real Decreto 2159/1978, de 23 de Junio, por el que se aprueba el Reglamento de Planeamiento para el Desarrollo y Aplicación de la Ley sobre Régimen del Suelo y Ordenación Urbana.

${ }^{155}$ Como por ejemplo el Ayuntamiento de Langreo (Asturias), que procedió a suspender durante un año las licencias urbanísticas para la ejecución de las instalaciones de telefonía móvil (licencias de obra y de actividad) en todo el término municipal mientras procedía al estudio de la elaboración de una Ordenanza reguladora de las mismas a incluir en el Plan General de Ordenación Urbana (PGOU). Boletín Oficial de Asturias $\mathrm{n}^{\mathrm{0}} 72$, del martes 27 de marzo de 2001.

${ }^{156}$ Por ejemplo, el Ayuntamiento de Teruel, el 27 de marzo de 2001, que llevó a cabo en los mismos días la misma suspensión de licencias, con el mismo objeto y con el mismo plazo, pero fundamentándose en el art. 65 y ss de la Ley Urbanística de Aragón. Boletín Oficial de Aragón de 14 de marzo de 2001.
} 
La doctrina y la jurisprudencia han tendido a considerar ilícitas éstas medidas fundamentándose en una interpretación restrictiva del art. 118.1 RP, según la cual la finalidad de esta suspensión es "impedir que se consumen actos de edificación y uso del suelo que, conformes con el planeamiento en vigor, pugnen con las previsiones del nuevo planeamiento deseable y puedan desvirtuar la efectividad de ellas"157.

Esta interpretación es criticable. Como señala DOMÉNECH PASCUAL, esta suspensión podría ampararse en la genérica obligación de los poderes públicos de proteger los derechos fundamentales a la vida y a la integridad física, ya que se trata ésta de una obligación positiva ${ }^{158}$ y a la cual están vinculados los poderes públicos la margen o incluso en contra de lo dispuesto en las leyes, tal y como establece la jurisprudencia constitucional ${ }^{159}$. Además, es pertinente la aplicación del principio de precaución a este caso, suspendiendo temporalmente la vigencia, no sólo del art. 118.1 RP, sino también, más en general, del art. 29.1 LGT, que prohíbe la imposición de restricciones absolutas al derecho de ocupación del dominio público y privado de los operadores. Conforme a la jurisprudencia comunitaria, dicha medida podría perfectamente ser considerada proporcional ${ }^{160}$.

Otros municipios han procedido a la denegación individual de licencias por motivos ambientales o sanitarios, cuestión que ha originado una gran conflictividad que la jurisprudencia ha resuelto favorable ${ }^{161}$ o negativamente ${ }^{162}$.

Algunas Ordenanzas Municipales fijan valores límite de emisión más estrictos que la normativa estatal o autonómica, en ocasiones utilizando los valores de referencia de la Conferencia de Salzburgo $\left(0,1 \mu \mathrm{W} / \mathrm{cm}^{2}\right)^{163}$, o incluso más restrictivos. Un ejemplo de

${ }^{157}$ STS de 16 de febrero de 1993, FJ 1º. En el mismo sentido, vid. QUIRÓS ROLDÁN, A, ESTELLA LÓPEZ, J.M, ARENAS SALVATIERRA, S., Estudio-comentario jurisprudencial sobre las licencias urbanísticas, Comares, 1997, p. 445.

${ }^{158}$ Como reconocen por ejemplo la STC 53/1985 (FJ $4^{\circ}$ ) y la STC $181 / 2000\left(\mathrm{FJ} 8^{\circ}\right)$.

${ }^{159} \mathrm{STC}^{80 / 1992}\left(\mathrm{FJ}^{\circ}\right.$ ) y STC 31/1994 (FJ $\left.7^{\circ}\right)$, por ejemplo.

${ }^{160}$ Como ha señalado el Tribunal de Primera Instancia en alguna ocasión, el carácter provisional de una medida precautoria puede, por sí misma, convertir ésta en proporcional. STPI Pfizer Animal Health, punto. 460.

${ }^{161}$ STSJ de Castilla y León, Sala de lo Contencioso-Administrativo, Valladolid, de 8 de febrero de 2001 (JUR 2001\124224), FJ $3^{\circ}$.

162 STSJ de Andalucía, Sevilla, Sala de lo Contencioso-Administrativo, Sección $2^{\mathrm{a}}$, de 29 de octubre de 2002, (JUR 2003\66386) FJ $3^{\circ}$ y STSJ de Madrid, de 4 de mayo de 2007 (JUR 2007\322525), FJ $7^{\circ}$..

${ }^{163}$ Por ejemplo, la Ordenanza de Castro Urdiales, Boletín Oficial de Cantabria n ${ }^{\mathrm{o}} 145$, de 30 de julio de 2002, en su art. 6.1.1, la Ordenanza de Marina de Cudeyo, Boletín oficial de Cantabria $n^{\circ} 117$, de 17 de 
protección realizada conforme a las recomendaciones internacionales más restrictivas es el de la Ordenanza de Molina de Segura de diciembre de $2007^{164}$, cuyo art. 10.2 prevé como nivel de referencia el de $0,1 \mu \mathrm{W} / \mathrm{cm}^{2}$ de Salzburgo, pero, además, endurece dicha limitación a $0,01 \mu \mathrm{W} / \mathrm{cm}^{2}$ en el interior de las casas ${ }^{165}$.

Esta posibilidad ha sido en muchas ocasiones rechazada por la jurisprudencia en la medida en que no se reconoce a los municipios la competencia para dictar normas adicionales de protección en materia ambiental y la política de valores límite se considera unánimemente como ejercicio de competencias ambientales ${ }^{166}$. En otras ocasiones, en cambio, la jurisprudencia ha amparado la imposición municipal de los niveles de Salzburgo, reconociendo el carácter de mínimos de los valores estatales ${ }^{167}$.

Algunas Ordenanzas han establecido la obligación para los titulares de las instalaciones de minimizar sus emisiones tanto como sea técnicamente posible ${ }^{168}$, y en algunos casos prevén también la posibilidad de revisar las licencias que se concedan con dichas condiciones con objeto de modificarlas adaptándolas a la técnica más avanzada ${ }^{169}$.

junio de 2008, en su art. 15, o la antigua Ordenanza de Granada de 19 de julio de 2001, BOP n ${ }^{\circ} 164$, en su art. 4 (Ordenanza hoy derogada por la que aparece más abajo).

${ }^{164}$ Boletín Oficial de la Región de Murcia, núm. 298, de 28 de diciembre de 2007.

${ }^{165}$ Nótese que, de implementarse dicha medida en el plazo de 2 años que la Ordenanza de Molina de Segura prescribe, la protección frente a los CEM en dicho municipio sería nada menos que 100.000 veces mayor que la que proporciona el RPSER.

${ }^{166}$ Así, "no pueden ejercerse las competencias urbanísticas para imponer limitaciones que traen causa de la preocupación en salud o medio ambiental...", STSJ de Andalucía de 18 de marzo de 2003, (RJCA 2003\869) $\left(\mathrm{FJ} \mathrm{5}^{\circ}\right)$. En el mismo sentido, la STSJ de Valencia, de 9 de febrero de 2007 (FJ $6^{\circ}$ ), la STSJ de la Región de Murcia, de 17 de noviembre de 2006, FJ 3º o la STSJ de Castilla-La Mancha, de 2 de julio de $2007, \mathrm{FJ} 4^{\circ}$.

167 STSJ de Cantabria de 17 de junio de 2003 (RJCA 2003\916).

168 Así, por ejemplo, el art. 10 de la Ordenanza de Molina de Segura prescribe, como una limitación general de las instalaciones, "que se utilicen todas las posibilidades técnicas existentes para garantizar a la ciudadanía la mínima exposición posible (principio ALATA)".

${ }^{169}$ Es el caso de la Ordenanza municipal sobre instalación de antenas en general y para la instalación y funcionamiento de instalaciones de radiocomunicación de telefonía móvil en el término municipal de Castro Urdiales. Boletín Oficial de Cantabria no 145, de 30 de julio de 2002. El TSJ de Cantabria juzgó lícita esta medida en su STSJ de Cantabria de 17 de junio de 2003 (RJCA 2003\916). Otra parte de la jurisprudencia, en cambio, ha negado que el municipio tenga competencias sobre la fijación de criterios tecnológicos sobre las características y el funcionamiento de las instalaciones de radiocomunicación (Por ejemplo, la STSJ de Valencia, de 16 de febrero de 2005 (RJCA 2005\229). 
Otra de las medidas que los Ayuntamientos han adoptado con el fin de proteger la salud de los efectos inciertos de la radiación no ionizante es la fijación de distancias mínimas de las estaciones de radiocomunicación: el llamado criterio de "evitación prudente"

Con carácter general, la doctrina y la jurisprudencia han juzgado lícitas dichas medidas cuando considera que el alejamiento es una medida urbanística ${ }^{171}$, e ilícitas cuando la considera medioambiental $^{172}$. En realidad, desde una perspectiva técnica, el alejamiento de las antenas del casco urbano no necesariamente conlleva una reducción de las emisiones a las que la población se ve expuesta, de no venir acompañado por la fijación de unos valores límite de emisión más estrictos. Dentro del amplio margen que el RPSER permite, el alejamiento ocasiona que los aparatos celulares deban esforzarse más para encontrar cobertura $\mathrm{y}$, por lo tanto, emitan a mayor intensidad de potencia, como señaló la CMT en su informe sobre la Ordenanza de Coria del Río ${ }^{173}$. Al mismo tiempo, las antenas también tienen que aumentar su potencia de emisión para garantizar la cobertura, por lo que la exposición de la población a CEM aumenta por doble partida. Por lo tanto, el alejamiento de las antenas de los núcleos urbanos resulta una medida desproporcionada, pero no por producir extensos costes a las operadoras en la garantía de la cobertura territorial, sino porque es contraproducente. Así, dicha medida precautoria no resulta adecuada ${ }^{174}$, y puede por lo tanto considerarse que tiene un carácter manifiestamente inapropiado para la consecución del fin perseguido (la

\footnotetext{
170 Fija una distancia mínima de $250 \mathrm{~m}$ respecto a viviendas, por ejemplo, la Ordenanza de Castro Urdiales en su art. 6. Otros municipios han fijado distancias diferentes, en ocasiones más restrictivas. Por ejemplo, en la Ordenanza de Marina de Cudeyo de 3 de junio de 2008 se fija con carácter general un mínimo de 500 metros respecto de edificios habitados.

${ }^{171}$ STSJ de Andalucía, Sevilla, de 1 de marzo de 2006, FFJJ $8^{\circ}$ y $9^{\circ}$.

172 de la Región de Murcia, de 24 de febrero de 2006 (JUR 2007\4480), FJ 2º . En el mismo sentido, la STSJ de la Comunidad Autónoma de les Illes Balears de 22 de febrero, FJ 5º y la STSJ de la Región de Murcia, de 17 de noviembre (RJCA 2007\362), FJ $3^{\circ}$.

${ }^{173}$ Este aspecto lo puso de relieve la CMT en su Informe 7/02/2002, de 21de febrero, sobre la Ordenanza Municipal reguladora de las instalaciones de telecomunicaciones del Municipio de Coria del Río (Sevilla). Recuperado el 1 de mayo de 2010 de http://www.localret.es/dret/iradioc/docs/cmt4.pdf.

174 Mantiene dicha opinión también DOMÉNECH PASCUAL, G., "El control Municipal de la Contaminación Electromagnética" cit, p. 629. La solución técnica que mejor permitiría reducir las emisiones (tanto de las antenas como de los aparatos celulares) sería precisamente la instalación de muchas más antenas emitiendo cada una a una potencia mucho menor. Ello permitiría reducir la exposición global y, además, distribuirla de un modo equitativo entre los habitantes del municipio. Sin embargo, ocasionaría daños al paisaje urbano y mayores costes económicos a las operadoras, que se verían obligadas a pagar la instalación de un número mucho mayor de infraestructuras de radiocomunicación.
} 
protección de la salud pública), lo que conforme a la jurisprudencia comunitaria determina la ilegitimidad de la medida precautoria afectada ${ }^{175}$.

Otra medida de alejamiento, compatible con la anterior, y que tampoco ha sido llevada a cabo en nuestro país, es la creación de zonas blancas libres de radiación. Las zonas blancas exigen un alejamiento de las antenas de una determinada demarcación, pero también una reducción de la potencia de emisión de éstas, ya que no se requiere garantizar cobertura alguna en dicha zona. Su objeto, por el contrario, es precisamente garantizar la existencia de un espacio urbano libre de radiación, donde puedan establecer su residencia las personas que sufren de electrosensibilidad y que no pueden vivir en ningún otro sitio.

Muchas Ordenanzas exigen un seguro de responsabilidad civil y la prestación obligatoria de fianza por parte de los operadores. Estas medidas han sido consideradas generalmente ilícitas por la jurisprudencia, al requerir el apoyo de una previsión legal conforme a la Ley 50/1980 del Contrato del Seguro ${ }^{176}$.

Otras Ordenanzas prevén un régimen de inspección y sancionador. El mismo aparece en el Modelo de Ordenanza Municipal de la FEMP y no plantea ningún problema, al resultar coherente con el Título XI de la LrBRL, introducido en 2003 por la Ley de Modernización del Gobierno Local ${ }^{177}$.

Otras medidas contenidas en las Ordenanzas Municipales, como la exigencia de un plan previo de implantación de red, medidas de protección del paisaje o la imposición del uso compartido de instalaciones, son ajenas a la protección sanitaria y por lo tanto no requieren ser estudiadas aquí.

En conclusión, comprobamos que es en los niveles autonómico y local -los más cercanos al ciudadano y los más alejados de la Industria- donde se ha comenzado antes a gestionar los riesgos de la radiación no ionizante. Urge la aplicación del principio comunitario de precaución a al sector. Tal aplicación exige, como mínimo, una

\footnotetext{
${ }^{175}$ Así, dice el TPI que tan solo el carácter manifiestamente inapropiado de una medida precautoria puede afectar a la legalidad de la misma. STPI Pfizer Animal Health, ap. 412.

${ }^{176}$ STSJ de Cantabria de 17 de junio de 2003 (RJCA 2007\362), FJ $17^{\circ}$ y $23^{\circ}$. En el mismo sentido, la STSJ de Murcia de 30 de enero de 2003 y la STSJ de Cataluña de 12 de febrero de 2004.

${ }^{177}$ Ley 57/2003, de 16 de diciembre de Modernización del Gobierno Local. Dicha Ley modificó el art. 129.1 LPC e introdujo un Título en la LrBRL, para resolver la discusión doctrinal y jurisprudencial sobre la capacidad de los municipios para dotarse de un régimen de infracciones y sanciones propio. Sobre el particular vid. VELASCO CABALLERO, F., DÍEZ SASTRE, S., "Ordenanzas municipales y reserva de Ley sancionadora", Cuadernos de Derecho Local, núm. 5, junio de 2004, pp. 50-62.
} 
evaluación del riesgo que tenga en cuenta los informes científicos más recientes y alarmantes ${ }^{178}$ sobre unos riesgos sanitarios muy graves en continua expansión.

\section{BIBLIOGRAFÍA}

AUSFELD-HAFTER, B, MANSER, R, KEMPF, D, BRÄNDLI, I., Elektrosensibilität und Komplementärmedizin - Eine Fragebogenerhebung in schweizerischen Arztpraxen mit komplementärmedizinischem Diagnostik - und Therapieangebot, BUWAL-Bern Universität, Bern, Juli 2005.

BIOINITIATIVE. (2007) A Rationale for a Biologically-Based Public Exposure Standard for Electromagnetic Fields (ELF and RF). Recuperado el 1 de mayo de 2010 de: http://www.bioinitiative.org.

BUNDESAMT FÜR STRAHLENSCHUTZ, Anhörung des Ausschusses für Umwelt und Verbraucherschutz des Bayerischen Landtages zum Thema "Einfluss des Mobilfunks auf die menschliche Befindlichkeit”, de 7 de diciembre de 2006.

CASSESE, S., I Beni pubblici, Giuffrè, Milán, 1969.

COMISIÓN EUROPEA. (1 de septiembre de 2008). Segundo Informe sobre la aplicación de la Recomendación del Consejo que limita la exposición del público en general a los campos electromagnéticos (o Hz a $300 \mathrm{GHz}$ ), COM (2008) 532 final. Recuperado el 1 de mayo de 2010 de: www.europa.eu.int.

— "Special Eurobarometer 272a / Wave 62.2 - TNS Opinion and Social. Fieldwork October-November 2006”, Bruselas, Junio 2007.

- (2002). Informe sobre la aplicación de la Recomendación del Consejo que limita la exposición del público en general a los campos electromagnéticos (o $\mathrm{Hz}$ a $300 \mathrm{GHz}$ ). $\begin{array}{lllllll}\text { Recuperado } & \text { el } & 1 & \text { de } & \text { mayo } & \text { de } & 2010\end{array}$ http://www.mityc.es/Nivelesexposicion/Secciones/UEuropea/.

CHINCHILLA MARÍN, C., La radiotelevisión como servicio público esencial, Tecnos, Madrid, 1988.

DOMÉNECH PASCUAL, G., "El control Municipal de la Contaminación Electromagnética", ESTEVE PARDO, José (dir.), Derecho del Medio Ambiente y Administración Local, Fundación Democracia y Gobierno Local, Madrid, 2006.

\footnotetext{
${ }^{178}$ La Comisión Europea, en su Comunicación sobre el recurso al principio de precaución (COM (2000), 1 , final, de 2 de febrero de 2000), destaca que cuando el riesgo no ha podido ser caracterizado y persisten múltiples hipótesis sobre el mismo, se debería optar por la hipótesis más pesimista (Anexo III).
} 
DOMÉNECH PASCUAL, G., "La deficiente regulación del riesgo electromagnético creado por las instalaciones eléctricas", RADA, núm.6, 2004.

DRAPER, G; VINCENT, T; KROLL, M.E; SWANSON., J., "Childhood cancer in relation to distance from high voltage power lines in England and Wales: a case-control study", British Medical Journal, núm. 330, 2005.

EBERHARDT, J.L, et al., "Blood-brain barrier permeability and nerve cell damage in rat brain 14 and 28 days alter exposure to microwaves from GSM mobile phones", Electromagnetic Biology and Medicine, núm. 27, 2008.

EMBID TELLO, A.E., Precaución y Derecho. El caso de los campos electromagnéticos, Iustel, Madrid, 2010.

FERNANDO PABLO, M.M., "Sobre el dominio público radioeléctrico: espejismo y realidad", $R A P, \mathrm{n}^{\circ} .143$, mayo-agosto de 1997.

FIRSTENBERG, A. (2006, enero). "The largest biological experiment ever". Sun Monthly. Recuperado el 1 de mayo de 2010 de www.sunmonthly.com/firstenberg.htm.

FORTES MARTÍN, A., "Comentario a la sentencia de la Sala de lo ContenciosoAdministrativo del TSJ Castilla y León de 8 de febrero de 2001", RIGA, 36, diciembre de 2002.

GARCÍA DE ENTERRÍA, E., La Ejecución autonómica de la legislación del Estado, Civitas, Madrid, 1984.

GARCÍA VITORIA, I.., Prohibiciones ambientales y libertad de empresa, Lex Nova, Valladolid, 2004.

HALLBERG, Ö, y OBERFELD, G., "Letter to the Editor: Will we all become electrosensitive?", Electromagnetic Biology and Medicine, núm. 25, 2006.

HERNANDO GRANDE, A., "Exposición a campos electromagnéticos: características y restricciones para evitar perjuicios a la salud", RIGA. Marzo de 2002.

HERRERA DEL REY, J.J., “Antenas y principio de precaución. La imprescindible exigencia de licencia de actividad previa a su instalación”, Diario La Ley, núm. 6473, 2006.

HORGUÉ BAENA, C., "El espectro radioeléctrico. Delimitación conceptual y calificación jurídica en el derecho español”, Justicia Administrativa, número extraordinario sobre propiedades públicas, 2006.

HUSS, A, SPOERRI, A, EGGER, M y RÖÖSLI, M., "Residence near power lines and mortality from neurodegenerative diseases: longitufinal study of the Swiss population", American Journal of Epidemiology, 5 de noviembre de 2008. 
ICNIRP., "Directrices para limitar la exposición eléctricos, magnéticos y electromagnéticos (hasta 300 GHz)", Health Physics, vol. 74, nº 4, 1998.

JOHANSSON, O., "Electrohypersensitivity: State-of-the-Art of a Functional Impairment", Electromagnetic Biology and Medicine, núm. 25, 2006.

MINISTERIO DE CIENCIA Y TECNOLOGÍA. (2003, abril). Informe sobre la exposición del público en general a las emisiones radioeléctricas de estaciones de radiocomunicación. Recuperado el 1 de mayo de 2010 de www.setsi.mcyt.es/movil/top_mov.htm.

MINISTERIO DE SANIDAD Y CONSUMO. (2005, agosto). Informe sobre la aplicación del Real Decreto 1066/2001, de 28 de septiembre, por el que se aprueba el Reglamento que establece condiciones de protección del dominio público radioeléctrico, restricciones a las emisiones radioeléctricas y medidas de protección sanitaria frente a emisiones radioeléctricas. V2. Recuperado el 1 de mayo de 2010 de http://www.msc.es/ciudadanos/saludAmbLaboral/docs.

MOLINA GIMÉNEZ, A., Las Antenas de Telefonía Móvil. Régimen Jurídico, Aranzadi. Navarra, 2002.

MUÑOZ MACHADO, S., Tratado de Derecho Administrativo y Derecho Público General, Vol. III, Iustel, Madrid, 2009.

PARLAMENTO EUROPEO. (2009, 2 de abril), Resolución sobre las consideraciones sanitarias relacionadas con los campos electromagnéticos. 2008/2211(INI). Recuperado el 1 de mayo de 2010 de http://www.europarl.europa.eu/sides/getDoc.do?pubRef=//EP//TEXT+TA+P6-TA-2009-0216+0+DOC+XML+V0//ES.

- Proposición de Resolución sobre las preocupaciones en cuanto a los efectos para la salud de los campos electromagnéticos. 2008/2211 (INI).

- (2008, 4 de septiembre). Resolución sobre la Revisión intermedia del Plan de Acción Europeo sobre Medio Ambiente y Salud 2004-2010. Recuperado el 1 de mayo de 2010 de http://www.europarl.europa.eu/sides/getDoc.do?pubRef=-//EP//TEXT+TA+P6-TA-2008$\underline{0410+0+\mathrm{DOC}+\mathrm{XML}+\mathrm{V} 0 / / \mathrm{ES} \& \text { language }=\mathrm{ES}}$. PARLAMENTO EUROPEO - DIRECCIÓN GENERAL DE INVESTIGACIÓN (DIRECCIÓN A), Los efectos fisiológicos y medioambientales de la radiación electromagnética no ionizante. PE, $\mathrm{n}^{\circ} 297.574$, marzo de 2001.

PAWL, R., "Cell phones more dangerous than cigarettes!", Surgical Neurology, Vol 70, Issue 5, November 2008. 
PORTOLÉS, M., "Mentiras, estadísticas y telecomunicaciones", Levante, EMV, 17 de mayo de 2007.

QUIRÓS ROLDÁN, A, ESTELLA LÓPEZ, J.M, ARENAS SALVATIERRA, S., Estudiocomentario jurisprudencial sobre las licencias urbanísticas, Comares, 1997.

RODRÍGUEZ-CHAVES MIMBRERO, B., "El ámbito de regulación de la normativa municipal en materia de telefonía móvil”, $R D U$, Año XLII, núm. 242, junio de 2008.

SANTAMARÍA ARINAS, R.J., "La normativa estatal sobre campos electromagnéticos generados por estaciones radioeléctricas", RADA, núm. 2, 2003.

- "Contaminación electromagnética y Derecho Ambiental. Las pautas de la política comunitaria y el modelo italiano", Revista Electrónica de Derecho Ambiental, núm. 8, Diciembre de 2002.

SANZ LARRUGA, F.J., La protección jurídica ante las radiaciones y la contaminación electromagnética (monografía), RADA, núm. 4, 2004.

SCENIHR. (16-21 de marzo de 2007). Posible effects of Electromagnetic Fields (EMF) on Human Health. Recuperado el 1 de mayo de 2010 de www.europa.eu.int.

SIBINA TOMÁS, D., "Las ordenanzas municipales reguladoras de las instalaciones de radiocomunicación”, Cuadernos de Derecho Local, núm. 0, 2002.

STRAHLENSCHUTZKOMMISSION. (1 de mayo de 2010). Grenzwerte und Vorsorgemaßnahmen zum Schutz der Bevölkerung vor elektromagnetischen Feldern. Recuperado el 1 de mayo de 2010 de http://www.ssk.de/werke/kurzinfo/2001/ssk0103.htm.

TARDÍO PATO, J.A., "Instalaciones de Telefonía Móvil, salud y medio ambiente", RADA, núm. 3, 2003.

VELASCO CABALLERO, F. DÍEZ SASTRE, S., "Ordenanzas municipales y reserva de Ley sancionadora", Cuadernos de Derecho Local, núm. 5, junio de 2004.

VIDA FERNÁNDEZ, J., "El conflicto de competencias en la intervención pública sobre las instalaciones de radiocomunicaciones: una resolución precipitada", Derecho y nuevas tecnologías (monografía); Revista de la Facultad de Derecho de la Universidad de Granada, $3^{\mathrm{a}}$ época, núm. 8, 2005.

WILLIAMS, C., "Cellphones affect human cells without heating them", New Scientist, 2619, 30 de agosto de 2007. 